\title{
Mechanism of trivalent actinide/lanthanide separation using synergistic mixtures of di(chlorophenyl)dithiophosphinic acid and neutral O-bearing co-extractants
}

\author{
Galina Ionova, ${ }^{a}$ Sergei Ionov, ${ }^{b}$ Catherine Rabbe, ${ }^{* c}$ Clément Hill, ${ }^{c}$ Charles Madic, ${ }^{c}$ \\ Robert Guillaumont, ${ }^{d}$ Giuseppe Modolo $^{e}$ and Jean Claude Krupa ${ }^{d}$ \\ ${ }^{a}$ Institute of Physical Chemistry, Russian Academy of Sciences, Lenin prospect 31, 1107907 \\ GSP-1, Moscow B-71, Russia \\ ${ }^{b}$ Kurnakov Institute of General and Inorganic Chemistry, Lenin prospect 31, 1107907 GSP-1, \\ Moscow B-71, Russia \\ ${ }^{c}$ CEA Valrhô-Marcoule, DEN/VRH/SCPS, B.P. 17171, 30207 Bagnols/Cèze, France. \\ E-mail: catherine.rabbe@cea.fr \\ ${ }^{d}$ Institute de Physique Nucléaire Orsay, Bât. 100, 91406 Orsay cedex, France \\ ${ }^{e}$ Institut fur Sichereitsforschung und Reaktortechnik, Forschungszentrum Jülich, Germany
}

\author{
Received (in Strasbourg, France) 7th August 2000, Accepted 12th December 2000 \\ First published as an Advance Article on the web 16th February 2001
}

\begin{abstract}
The mechanism of synergistic selective extraction of Am(III) over Eu(III) from aqueous nitric acid solutions using di(chlorophenyl)dithiophosphinic acid $\left[(\mathrm{Cl} \Phi)_{2} \mathrm{PSSH}\right]$ and neutral O-bearing organophosphorus co-extractants (B) has been investigated. $(\mathrm{Cl} \Phi)_{2} \mathrm{PSSH}$ forms weaker complexes with Am(III) than $\mathrm{R}_{2} \mathrm{PSSH}$ (where $\mathrm{R}=$ alkyl group). However, the $\mathrm{Am}(\mathrm{III}) /(\mathrm{Cl} \Phi)_{2} \mathrm{PSSH}$ complexes are stronger than the corresponding $\mathrm{Eu}(\mathrm{III}) /(\mathrm{Cl} \Phi)_{2} \mathrm{PSSH}$ complexes, although the difference is not as large as in the case of the corresponding complexes formed with $\mathrm{R}_{2} \mathrm{PSSH}$. The donor properties of co-extractants are also discussed. Chemical shifts in the ${ }^{31} \mathrm{P}$ NMR spectra of the organophosphorus co-extractants correlate qualitatively with the extractability of Am(III) and Eu(III) in $(\mathrm{Cl \Phi})_{2} \mathrm{PSSH}$

+ B synergistic mixtures. The synergistic effect determines the selectivity not only qualitatively but also quantitatively. The high selectivity observed using tri-2-ethylhexyl phosphate (T2EHP) is caused by a synergistic bonding effect for the Am(III) complex and an antagonistic effect for Eu(III).

A donor-acceptor mechanism is shown to promote Am(III) extraction for almost all B co-extractants. A contribution of entropy terms for extracted $\mathrm{Eu}(\mathrm{III})$ extraction is assumed to be significant. Interatomic distances $R_{\mathrm{Eu}-\mathrm{S}}$ in the Eu(III) complexes are calculated.

The softness of S-bearing extractants XYPSSH (with X and $\mathrm{Y}=\mathrm{R}, \mathrm{RO}$ or $\mathrm{ClC}_{6} \mathrm{H}_{4}$ ) is discussed from the point of view of the effective charge carried by the $\mathrm{S}$ atoms. The hardness of $\mathrm{Eu}(\mathrm{III})$ and $\mathrm{Am}$ (III) is evaluated.
\end{abstract}

Separation of the trivalent actinides/lanthanides [An(III)/ $\mathrm{Ln}(\mathrm{III})]$ groups is one of the key problems facing any new partitioning and transmutation nuclear waste management strategy being studied worldwide. ${ }^{1,2}$ In 1996, Zhu et al. ${ }^{3}$ demonstrated that sulfur-bearing acidic extractants, $\mathrm{R}_{2} \mathrm{PSSH}$ (where $\mathrm{R}=$ alkyl group), like Cyanex 301, exhibit extremely high efficiency for such a separation. Am/Eu separation factors $\left(\mathrm{SF}_{\mathrm{Am} / \mathrm{Eu}}\right)$ as high as 5900 were obtained. Unfortunately, reasonably high $\mathrm{Am}(\mathrm{III})$ distribution ratios $\left(D_{\mathrm{Am}}\right)$ were only observed for a $\mathrm{pH}$ range of 3 to 5 , which is not suitable for industrial process development. Attempts to shift the high Am(III) affinity to a practical low aqueous $\mathrm{pH}$ range, while maintaining high $\mathrm{SF}_{\mathrm{Am} / \mathrm{Eu}}$, were then carried out by using Cyanex 301 and O-bearing neutral co-extractants. ${ }^{4-6}$ Finally, Modolo et $a l^{7 a}$ were successful in modifying the nature of the substituents on dithiophosphinic acid. When replacing the alkyl groups $\mathrm{R}$ in $\mathrm{R}_{2} \mathrm{PSSH}$ with electronwithdrawing groups, like phenyl, tolyl or halogen-substituted phenyl groups, synergistic mixtures involving these new dithiophosphinic acids and O-bearing neutral organophosphorus co-extractants were found to be able to extract selectively An(III) over $\mathrm{Ln}$ (III) from acidic aqueous feeds $\left(C_{\mathrm{HNO}_{3}}\right.$ as high as $1.5 \mathrm{M}$ can be used for the best case). Among the synergistic mixtures studied by Modolo et al., ${ }^{7 a}$ the best for process development appears to be di(chlorophenyl)dithiophosphinic acid $\left[(\mathrm{Cl} \Phi)_{2} \mathrm{PSSH}\right]$ and tri- $n$-octylphosphine oxide (TOPO).

In a first paper, ${ }^{8}$ we attempted to interpret the mechanism of the $A n(\mathrm{III}) / \mathrm{Ln}$ (III) group separation observed with the synergistic mixture of Cyanex $301\left(\mathrm{R}_{2} \mathrm{PSSH}\right)$ and O-bearing neutral co-extractants. Numerous theoretical chemistry methods were used to interpret the observed $\mathrm{An}(\mathrm{III}) / \mathrm{Ln}(\mathrm{III})$ selectivity. It was demonstrated that high $\mathrm{SF}_{\mathrm{Am} / \mathrm{Eu}}$ values were due to a covalent effect in the $\mathrm{M}$ (III)-S bonds, which was greater for Am(III) than for Eu(III). This covalent effect could be controlled by the donor ability of the $\mathrm{O}$ atom of the neutral co-extractant.

The present article pursues the analysis using the data obtained by Modolo et al., ${ }^{7 a}$ on $\mathrm{Am}(\mathrm{III}) / \mathrm{Eu}(\mathrm{III})$ separation obtained with synergistic mixtures comprising $(\mathrm{Cl} \Phi)_{2} \mathrm{PSSH}$ and neutral organophosphorus co-extractants. Table 1 shows the names, acronyms and semi-developed formulae of the acidic S-bearing extractants and the neutral co-extractants (B), while Table 2 gives some of the experimental results obtained by Modolo et al. ${ }^{7 a}$ used as a database for this work. Table 3 presents the experimental data ${ }^{7 a}$ related to the influence of the nature of the diluent on $\mathrm{Am} / \mathrm{Eu}$ extraction and separation properties, also used as a database in this study. 
Table 1 Names, acronyms and semi-developed formulae of acidic S-bearing and neutral O-bearing extractants considered in this article

\begin{tabular}{|c|c|c|}
\hline Name & Acronym & Semi-developed formula \\
\hline Di(chlorophenyl)dithiophosphinic acid & $(\mathrm{Cl} \Phi)_{2} \mathrm{PSSH}$ & $\left(\mathrm{ClC}_{6} \mathrm{H}_{4}\right)_{2} \mathrm{PSSH}$ \\
\hline Bis(2,4,4-trimethylpentyl)dithiophosphinic acid & $\begin{array}{l}\text { Cyanex } 301 \text { or } \\
\text { HA or } \mathrm{R}_{2} \mathrm{PSSH}\end{array}$ & {$\left[\left(\mathrm{H}_{3} \mathrm{C}\right)_{3} \mathrm{CCH}_{2} \mathrm{CH}\left(\mathrm{CH}_{3}\right) \mathrm{CH}_{2}\right]_{2} \mathrm{PSSH}$} \\
\hline Di(2-ethylhexyl)dithiophosphoric acid & $\mathrm{D}_{2}$ EHDTPA & {$\left[\mathrm{H}_{3} \mathrm{C}\left(\mathrm{CH}_{2}\right)_{3} \mathrm{CH}\left(\mathrm{C}_{2} \mathrm{H}_{5}\right) \mathrm{CH}_{2} \mathrm{O}_{2} \mathrm{PSSH}\right.$} \\
\hline Trimethyl phosphate & TMP & $\left(\mathrm{H}_{3} \mathrm{CO}\right)_{3} \mathrm{P}=\mathrm{O}$ \\
\hline Tri- $n$-butyl phosphate & TBP & $\left(\mathrm{H}_{9} \mathrm{C}_{4} \mathrm{O}\right)_{3} \mathrm{P}=\mathrm{O}$ \\
\hline Tri- $n$-hexyl phosphate & THP & $\left(\mathrm{H}_{13} \mathrm{C}_{6} \mathrm{O}\right)_{3} \mathrm{P}=\mathrm{O}$ \\
\hline Tri- $n$-octyl phosphate & TOP & $\left(\mathrm{H}_{17} \mathrm{C}_{8} \mathrm{O}\right)_{3} \mathrm{P}=\mathrm{O}$ \\
\hline Tri-tert-butyl phosphate & $\mathrm{T} t \mathrm{BP}$ & {$\left[\left(\mathrm{H}_{3} \mathrm{C}\right)_{3} \mathrm{CO}\right]_{3} \mathrm{P}=\mathrm{O}$} \\
\hline Tri-2-ethylhexyl phosphate & T2EHP & {$\left[\mathrm{H}_{3} \mathrm{C}\left(\mathrm{CH}_{2}\right)_{3} \mathrm{CH}\left(\mathrm{C}_{2} \mathrm{H}_{5}\right) \mathrm{CH}_{2} \mathrm{O}_{3} \mathrm{P}=\mathrm{O}\right.$} \\
\hline Triphenyl phosphate & TPP & $\left(\mathrm{C}_{6} \mathrm{H}_{5} \mathrm{O}\right)_{3} \mathrm{P}=\mathrm{O}$ \\
\hline Triallyl phosphate & TAP & $\left(\mathrm{CH}_{2}=\mathrm{CHCH}_{2} \mathrm{O}\right)_{3} \mathrm{P}=\mathrm{O}$ \\
\hline Dibutyl butylphosphonate & $\mathrm{DB}[\mathrm{BP}]$ & $\left(\mathrm{H}_{9} \mathrm{C}_{4} \mathrm{O}\right)_{2}\left(\mathrm{H}_{9} \mathrm{C}_{4}\right) \mathrm{P}=\mathrm{O}$ \\
\hline Di(2-ethylbutyl) 2-ethylbutylphosphonate & $\mathrm{D}(\mathrm{EB})[(\mathrm{EB}) \mathrm{P}]$ & {$\left[\left(\mathrm{H}_{3} \mathrm{C}\right)_{2} \mathrm{CHCH}_{2} \mathrm{CH}\left(\mathrm{CH}_{3}\right) \mathrm{O}\right]_{2}\left(\mathrm{H}_{9} \mathrm{C}_{4}\right) \mathrm{P}=\mathrm{O}$} \\
\hline Di(4-methylpentyl-2) butylphosphonate & $\mathrm{D}(4-\mathrm{Mpe}-2)[\mathrm{BP}]$ & {$\left[\left(\mathrm{H}_{5} \mathrm{C}_{2}\right)_{2} \mathrm{CHCH}_{2} \mathrm{O}_{2}\left[\left(\mathrm{H}_{5} \mathrm{C}_{2}\right)_{2} \mathrm{CHCH}_{2}\right] \mathrm{P}=\mathrm{O}\right.$} \\
\hline Butyl dibutylphosphinate & $\mathrm{B}[\mathrm{DBP}]$ & $\left(\mathrm{H}_{9} \mathrm{C}_{4} \mathrm{O}\right)\left(\mathrm{H}_{9} \mathrm{C}_{4}\right)_{2} \mathrm{P}=\mathrm{O}$ \\
\hline Tri- $n$-butylphosphine oxide & TBPO & $\left(\mathrm{H}_{9} \mathrm{C}_{4}\right)_{3} \mathrm{P}=\mathrm{O}$ \\
\hline Tri- $n$-octylphosphine oxide & TOPO & $\left(\mathrm{H}_{17} \mathrm{C}_{8}\right)_{3} \mathrm{P}=\mathrm{O}$ \\
\hline Triphenylphosphine oxide & TPPO & $\left(\mathrm{H}_{5} \mathrm{C}_{6}\right)_{3} \mathrm{P}=\mathrm{O}$ \\
\hline Bis(2,4,4-trimethylpentyl)octylphosphine oxide & BPOPO & {$\left[\left(\mathrm{H}_{3} \mathrm{C}\right)_{3} \mathrm{CCH}_{2} \mathrm{CH}\left(\mathrm{CH}_{3}\right) \mathrm{CH}_{2}\right]_{2}\left(\mathrm{H}_{17} \mathrm{C}_{8}\right) \mathrm{P}=\mathrm{O}$} \\
\hline Tri-isobutylphosphine sulfide & TiBPS & {$\left[\left(\mathrm{H}_{3} \mathrm{C}\right)_{2} \mathrm{CHCH}_{2}\right]_{3} \mathrm{P}=\mathrm{S}$} \\
\hline$n$-Octyl(phenyl)- $N, N$-di-isobutylcarbamoylmethylphosphine oxide & CMPO & $\left(\mathrm{H}_{17} \mathrm{C}_{8}\right)\left(\mathrm{C}_{6} \mathrm{H}_{5}\right) \mathrm{P}(\mathrm{O}) \mathrm{CH}_{2} \mathrm{C}(\mathrm{O}) \mathrm{N}\left[\mathrm{CH}_{2} \mathrm{CH}\left(\mathrm{CH}_{3}\right)_{2}\right]_{2}$ \\
\hline$N, N^{\prime}$-Di(ethyl-2-hexyl)dimethyl-2,2-butanamide & D2EHDMBA & $\left(\mathrm{H}_{3} \mathrm{C}\right)_{3} \mathrm{CCH}_{2} \mathrm{C}(\mathrm{O}) \mathrm{N}\left[\mathrm{CH}_{2} \mathrm{CH}\left(\mathrm{C}_{2} \mathrm{H}_{5}\right) \mathrm{C}_{4} \mathrm{H}_{9}\right]_{2}$ \\
\hline$N, N^{\prime}$-Dimethyl- $N, N^{\prime}$-dibutyltetradecylmalonamide & $\mathrm{C} 14$ & {$\left[\left(\mathrm{CH}_{3}\right)\left(\mathrm{C}_{4} \mathrm{H}_{9}\right) \mathrm{NC}(\mathrm{O})\right]_{2} \mathrm{CHC}_{14} \mathrm{H}_{29}$} \\
\hline
\end{tabular}

\section{Methods}

Quantum chemistry calculations were performed with the GAUSSIAN 98 code $^{9}$ on a Silicon Graphics bi-processor workstation at CEA/Marcoule. The $a b$ initio calculations used a 6-31G* basis set. The molecular geometry of all coextractants and S-bearing extractants was fully optimized and the Mulliken net atomic charges were computed.

Table 2 Extraction of $\mathrm{Am}(\mathrm{III})$ and $\mathrm{Eu}(\mathrm{III})$ from aqueous nitric acid $(0.2 \mathrm{M})$ by synergistic mixtures of $(\mathrm{Cl} \Phi)_{2} \mathrm{PSSH}(0.5 \mathrm{M})$ and $\mathrm{B}(0.25 \mathrm{M})$ in toluene (room temperature) and energy of the visible charge transfer band $[E(\mathrm{~S} \rightarrow \mathrm{Eu})]$ observed for some extracted $E u(I I I)$ organic phases $^{7}$

\begin{tabular}{lclcl}
\hline B & $D_{\text {Am(III) }}{ }^{a}$ & $D_{\mathrm{Eu}(\mathrm{III})}{ }^{a}$ & $\mathrm{SF}_{\mathrm{Am} / \mathrm{Eu}}{ }^{b}$ & $E(\mathrm{~S} \rightarrow \mathrm{Eu}) / \mathrm{eV}$ \\
\hline TMP & 0.0046 & 0.00037 & 12.3 & \\
TBP & 2.13 & 0.068 & 31.2 & 3.08 \\
THP & 1.59 & 0.033 & 48.3 & \\
TOP & 1.06 & 0.002 & 687.0 & \\
T2EHP & 1.28 & 0.001 & 1056.7 & \\
TPP & 0.0017 & 0.00022 & 8.1 & 3.05 \\
TAP & 0.477 & 0.015 & 32.1 & \\
TBPO & 76.52 & 4.130 & 18.5 & \\
TOPO & 152.25 & 5.46 & 27.9 & 3.12 \\
TPPO & 69.5 & 1.800 & 38.5 & \\
BPOPO & 1.73 & 0.069 & 24.7 & \\
TiBPS & 0.02 & 0.002 & 10.2 &
\end{tabular}

${ }^{a} D_{\mathrm{M}}=C_{\mathrm{M}}^{\mathrm{org}} / C_{\mathrm{M}}^{\mathrm{aq}}$ where $C_{\mathrm{M}}^{\mathrm{org}}$ and $C_{\mathrm{M}}^{\mathrm{aq}}$ are the $\mathrm{M}$ (III) organic and aqueous equilibrium concentrations, respectively. ${ }^{b} \mathrm{SF}_{\mathrm{Am} / \mathrm{Eu}}=$ $D_{\mathrm{Am}(\mathrm{III})} / D_{\mathrm{Eu}(\mathrm{III})}$

Table 3 Effect of the type of diluent on the extraction and separation of Am(III) and Eu(III) by a synergistic mixture of $(\mathrm{Cl} \Phi)_{2}$ PSSH (0.5 M) and TOPO $(0.25 \mathrm{M}$ ) (in $0.5 \mathrm{M}$ aqueous nitric acid at room temperature $)^{7}$

\begin{tabular}{lcll}
\hline Diluent & $D_{\text {Am(III) }}$ & $\mathrm{D}_{\mathrm{Eu}(\mathrm{III})}$ & $\mathrm{SF}_{\mathrm{Am} / \mathrm{Eu}}$ \\
\hline Toluene & 7.19 & 0.306 & 23.5 \\
Xylene & 8.83 & 0.385 & 22.9 \\
tert-Butylbenzene & 19.8 & 0.615 & 31.2 \\
Tri-isopropylbenzene & 55.8 & 1.23 & 45.6 \\
\end{tabular}

\section{Results and discussion}

\section{Hardness and softness in the separation of Am(III) and Eu(III) with acidic S-bearing extractants}

During the last decade, acidic S-bearing extractants, di(2-ethylhexyl)dithiophosphoric acid acid (D2EHDTPA), ${ }^{10}$ bis- $(2,4,4-$ trimethylpentyl)dithiophosphinic acid (Cyanex 301), ${ }^{3-5}$ di(chlorophenyl)dithiophosphinic acid, ${ }^{7}$ in synergistic mixtures with various neutral molecules involving a hard oxygen atom, were widely used in liquid-liquid extraction to separate An(III) from $\mathrm{Ln}$ (III) and, particularly, Am(III) from $\mathrm{Eu}(\mathrm{III})$. Numerous experimental data as well as a theoretical basis (as developed in the first paper of this series ${ }^{8}$ ) are used in order to briefly review and compare these extractants from the standpoint of their softness, and with respect to the hardness of Am(III) vs. Eu(III).

When used alone, the various acidic S-bearing extractants considered here exhibit different Am(III) and Eu(III) extraction abilities, expressed in terms of extraction equilibrium constants, $K_{\text {ex }}$. With (RO) ${ }_{2}$ PSSH $\quad(\text { D2EHDTPA })^{10}$ for $\mathrm{MA}_{3}$ extracted complexes $\left(\mathrm{A}^{-}=\mathrm{D}^{2} \mathrm{EHDTP}^{-}\right)$ $\log K_{\mathrm{ex} / \mathrm{Am}}=-8.1 \quad$ and $\log \quad K_{\mathrm{ex} / \mathrm{Eu}}=-8.3 \quad$ where $K_{\mathrm{ex}}=K_{\mathrm{ex}}=\left[\overline{\mathrm{MA}_{3}}\right]\left[\mathrm{H}^{+}\right]^{3}\left[\mathrm{M}^{3+}\right]^{-1}[\overline{\mathrm{HA}}]^{-3}$ (organic species are highlighted with an overbar). Using $\mathrm{R}_{2} \mathrm{PSSH}$ (Cyanex $301)^{5}$ for $\mathrm{MA}_{3} \cdot \mathrm{HA}$ extracted complexes $\left(\mathrm{A}^{-}=\right.$Cyanex 301 anion) $\log K_{\mathrm{ex} / \mathrm{Am}}=-7.72 \pm 0.07$ and $\log K_{\mathrm{ex} / \mathrm{Eu}}=-11.42$ \pm 0.08 where $K_{\mathrm{ex}}=\left[\overline{\mathrm{MA}_{3} \cdot \mathrm{HA}}\right]\left[\mathrm{H}^{+}\right]^{3}\left[\mathrm{M}^{3+}\right]^{-1}\left[\overline{\left.(\overline{\mathrm{HA}})_{2}\right]^{-3}}\right.$ with $(\mathrm{Cl} \Phi)_{2} \mathrm{PSSH}^{7}$ no extraction of $\mathrm{Am}$ (III) and $\mathrm{Eu}(\mathrm{III})$ for aqueous $0.2 \mathrm{M} \mathrm{HNO}_{3}$ was found. From these results, both $\mathrm{Am}$ (III) and Eu(III) can be considered as hard Lewis acids in the complexes with D2EHDTPA, although Am(III) seems to be a significantly softer Lewis acid than Eu(III) in the extracted complexes with Cyanex 301.

The softness character of bases, $s_{\mathrm{b}}$, corresponding to their ability to donate bonding electrons, is given in the literature. ${ }^{11}$ The softness character of acidic S-bearing extractants can also be considered. Their $s_{\mathrm{b}}$ should vary ${ }^{3-7,10}$ according to the series: $(\mathrm{RO})_{2} \mathrm{PSS}^{-}<\mathrm{R}(\mathrm{RO}) \mathrm{PSS}^{-}<(\mathrm{Cl} \Phi)_{2} \mathrm{PSS}^{-}<\mathrm{R}_{2} \mathrm{PSS}^{-}$. The softness of the $\mathrm{PSS}^{-}$groups depends significantly on the substituents of the $\mathrm{P}$ atoms of these molecules. The oxygen atoms in the RO substituents attract electron density from the $\mathrm{S}$ atoms, resulting in decreasing basicity (softness) of the $\mathrm{S}$ atoms. 
Table 4 Atomic and group charges calculated by ab initio quantum chemical methods in $\mathrm{XYPSS}^{-}$bases $(\mathrm{X}$ and $\mathrm{Y}=$ alkyl, aryl or alkoxy groups)

\begin{tabular}{lllll}
\hline & $Q(\mathrm{P})$ & $Q(\mathrm{~S})_{1}{ }^{a}$ & $Q(\mathrm{~S})_{2}{ }^{a}$ & $Q(\mathrm{PSS})$ \\
\hline $\mathrm{X}=\mathrm{Y}=\mathrm{R}$ & +0.743 & -0.667 & -0.668 & -0.592 \\
$\mathrm{X}=\mathrm{Y}=\mathrm{ClC}_{6} \mathrm{H}_{4}$ & +0.730 & -0.619 & -0.619 & -0.508 \\
$\mathrm{X}=\mathrm{R} ; \mathrm{Y}=\mathrm{OR}$ & +0.943 & -0.679 & -0.686 & -0.422 \\
$\mathrm{X}=\mathrm{Y}=\mathrm{OR}$ & +1.095 & -0.683 & -0.683 & -0.271
\end{tabular}

${ }^{a}$ The two $\mathrm{S}$ atoms of the ligands are almost equivalent, except in the case where $\mathrm{X} \neq \mathrm{Y}$.

Quantum chemical calculations using the $6-31 \mathrm{G}^{*}$ basis set are fully consistent with these extraction results for $\mathrm{R}_{2} \mathrm{PSSH}$ and $(\mathrm{Cl} \Phi)_{2} \mathrm{PSSH}$ extractants: the sulfur atoms in $\mathrm{R}_{2} \mathrm{PSS}^{-}$ have more negative charge than those in $(\mathrm{Cl} \Phi)_{2} \mathrm{PSS}^{-}$, as shown in Table 4. Moreover, the substituents $\mathrm{R}, \mathrm{RO}$ and $\mathrm{ClC}_{6} \mathrm{H}_{4}$ significantly change the effective charge on the functional group PSS $^{-}$. The softness of the dithiophosphinic acids depends on the effective charge on the $\mathrm{PSS}^{-}$moiety rather than only on the effective charges on the $\mathrm{S}$ atoms. This suggests that the extraction ability of dithiophosphinic acids is not only determined by the $\mathrm{M}-\mathrm{S}$ bonds but also by the $\mathrm{M}-\mathrm{P}$ repulsion.

According to a rough conventional view, ${ }^{12-14}$ hard cations (acceptors or Lewis acids) coordinate to various hard ligands (donors or Lewis bases) mainly by electrostatic interactions. Conversely, soft cations form covalent bonds with soft ligands. However, the literature demonstrates that hard Ln(III) Lewis acids can be coordinated simultaneously with hard (O) and soft $(\mathrm{S})$ donor atoms ${ }^{15}$ in ion-pair complexes such as $\left\{\mathrm{Ln}\left[\left(\mathrm{H}_{5} \mathrm{C}_{2} \mathrm{O}\right)_{2} \mathrm{PSS}\right]_{2}[\mathrm{TPPO}]_{2}\right\}^{+}\left\{\left(\mathrm{H}_{5} \mathrm{C}_{2} \mathrm{O}\right)_{2} \mathrm{PSS}\right\}^{-}$, where $\mathrm{Ln}=\mathrm{Nd}-\mathrm{Lu}$, or in neutral complexes of the type $\mathrm{Ln}\left[\left(\mathrm{H}_{5} \mathrm{C}_{2} \mathrm{O}\right)_{2} \mathrm{PSS}\right]_{3}[\mathrm{TPPO}]_{2}$, where $\mathrm{Ln}=\mathrm{La}-\mathrm{Pr}$.

The coexistence of soft and hard donor atoms in complexes with hard Ln(III) or An(III) Lewis acids is also known in the case of the extraction of $\mathrm{Am}$ (III) and $\mathrm{Eu}(\mathrm{III})$ by: (i) D2EHDTPA with $\mathrm{TBP}^{10}{ }^{10}$ (ii) purified Cyanex 301 in synergistic mixtures with TBP, T $t \mathrm{BP}$, TPP, TOPO, CMPO, D2EHDMBA and $\mathrm{C}_{14}{ }^{5}$ and by (iii) $(\mathrm{Cl} \Phi)_{2} \mathrm{PSSH}$ with $\mathrm{B}$ (Table 2). In ref. 8, it was shown that the mechanism of Am(III) and Eu(III) extraction by $\mathrm{R}_{2} \mathrm{PSSH}$ with a hard $(\mathrm{O})$ atom coextractant $\mathrm{B}$ is mainly governed by the change in the nature of the $\mathrm{M}-\mathrm{S}$ bond owing to the transfer of electron density in the system $\mathrm{O} \leftrightarrow \mathrm{M} \leftrightarrow \mathrm{S}$ : the hard $O$ atom controls the donor properties of the $S$ atoms in the acidic $S$-bearing extractant.

The combination of ligands with hard and soft donor atoms thus opens a wide range of possibilities for extraction in twophase systems. The interpretation of the formation of these mixed complexes within Pearson's theory is a new task for solvent extraction chemistry. A key question in this field is the relative position of $\mathrm{Am}$ (III) and $\mathrm{Eu}$ (III) [and, more generally, of the two series of trivalent ions An(III) and Ln(III)] in Pearson's useful cation hardness/softness classification, ${ }^{12,13}$ which is still used today. ${ }^{14,16}$ The high selectivity for Am(III) vs. Eu(III) in solvent extraction using extractants with soft $\mathrm{S}$ donor atoms significantly modifies the conventional presentation. ${ }^{11-14,16-18}$

According to Pearson, ${ }^{12,13}$ independently of their oxidation states, lanthanide and actinide ions as a group are classified as hard acids, but the position of the individual An(III) or Ln(III) ions on this hardness/softness scale is not known. This raises the following questions. (i) Does the hardness character $(h)$ of An(III) and Ln(III) change along the f-block families? (ii) What is the difference in $h_{\mathrm{a}}$ between corresponding $\operatorname{Ln}(\mathrm{III})$ and $\mathrm{An}$ (III) ions along both series of elements?

Pearson's qualitative concepts were treated quantitatively by several groups. ${ }^{11,16-18}$ The theory of hardness/softness based on quantum chemical perturbation theory was developed by Klopman ${ }^{11}$ and a quantitative scale of hardness $\left(h_{\mathrm{a}}\right)$ was established for many cations, including a single f element, $\mathrm{La}$ (III). In this section, these calculations are extended to all trivalent f-block ions. The frontier orbitals, that is the highest occupied molecular orbital of a donor atom (or base) and the lowest empty orbital of the acceptor atom (or acid) were considered. ${ }^{11}$ If the difference between these orbitals is large, very little electron transfer occurs from the donor to the acceptor atom, and the chemical bond is ionic. Conversely, partial charge transfer from the donor molecular orbital to the acceptor orbital results in covalent bonding. In this model, the electron transfer effect from the ligand $\mathrm{L}$ to the metal $\mathrm{M}(\mathrm{M} \leftarrow \mathrm{L})$ leads to covalent bonding and decreasing ionicity of the $\mathrm{M}-\mathrm{L}$ bond. Decreasing ionicity is more often responsible for a desolvation effect.

The hardness character $h_{\mathrm{a}}$, measured in energy units, is defined as:

$$
h_{\mathrm{a}}=-E_{\mathrm{orb}}+E_{\mathrm{des}}
$$

where $E_{\mathrm{orb}}$ and $E_{\mathrm{des}}$ are the atomic orbital energy of the free ion $\mathrm{M}(\mathrm{III})$ and its desolvation energy, respectively, $E_{\text {orb }}$ is given by:

$$
E_{\text {orb }}=I^{3+}-b^{2}\left(I^{3+}-I^{2+}\right)
$$

where $I^{3+}$ and $I^{2+}$ are the third and the second ionization potentials of $\mathrm{M}$, and $b^{2}$ is a variation parameter corresponding to the transferred electronic density. Klopman ${ }^{11}$ proposed a constant value for the $b^{2}$ parameter equal to 0.25 for all cations, independent of their charge ( $z=1$ to 4$). E_{\text {des }}$ is given by:

$$
E_{\text {des }}=C \times 1.268 \times R_{\mathrm{s}}^{-1}\left(1-\varepsilon^{-1}\right) \times\left(3-2 \times 1.268 \times b^{2}\right)
$$

where $C$ is a constant arising from unit conversions and is equal to $14.39 \mathrm{eV}, R_{\mathrm{s}}$ is the effective solvation radius of $\mathrm{M}$ and $\varepsilon$ is the dielectric constant of the medium.

The calculated hardness character $h_{\mathrm{a}}$ of $\mathrm{Ln}$ (III) and An(III) with the values of the different parameters used in the calcu-

Table 5 Calculated hardness character of Ln(III), Am(III) and Cm(III) and parameters used in eqn. (4)-(6). $R_{\mathrm{S}}$ is the effective solvation

\begin{tabular}{|c|c|c|c|c|c|c|c|}
\hline & $I^{2+} / \mathrm{eV}$ & $I^{3+} / \mathrm{eV}$ & $E_{\text {orb }} / \mathrm{eV}$ & $\Delta H_{\mathrm{h}} / \mathrm{eV}$ & $R_{\mathrm{s}} / \AA$ & $E_{\text {des }} / \mathrm{eV}$ & $h_{\mathrm{a}} / \mathrm{eV}$ \\
\hline $\mathrm{La}$ & 11.06 & 19.18 & 17.15 & 34.32 & 1.960 & 21.75 & 4.60 \\
\hline $\mathrm{Ce}$ & 10.85 & 20.2 & 17.86 & 34.82 & 1.932 & 22.07 & 4.20 \\
\hline $\operatorname{Pr}$ & 10.55 & 21.62 & 18.85 & 35.30 & 1.906 & 22.37 & 3.52 \\
\hline $\mathrm{Nd}$ & 10.73 & 22.1 & 19.26 & 35.62 & 1.888 & 22.57 & 3.32 \\
\hline $\mathrm{Pm}$ & 10.9 & 22.3 & 19.45 & 35.87 & 1.875 & 22.73 & 3.28 \\
\hline $\mathrm{Sm}$ & 11.07 & 23.4 & 20.32 & 36.10 & 1.863 & 22.88 & 2.56 \\
\hline $\mathrm{Eu}$ & 11.24 & 24.92 & 21.50 & 36.64 & 1.836 & 23.22 & 1.72 \\
\hline $\mathrm{Gd}$ & 12.09 & 20.63 & 18.50 & 36.80 & 1.828 & 23.32 & 4.83 \\
\hline $\mathrm{Tb}$ & 11.52 & 21.91 & 19.31 & 37.24 & 1.806 & 23.60 & 4.29 \\
\hline Dy & 11.67 & 22.8 & 20.02 & 37.31 & 1.803 & 23.65 & 3.63 \\
\hline Ho & 11.8 & 22.84 & 20.08 & 37.80 & 1.780 & 23.96 & 3.88 \\
\hline $\mathrm{Er}$ & 11.93 & 22.74 & 20.04 & 38.04 & 1.768 & 24.11 & 4.07 \\
\hline $\mathrm{Tm}$ & 12.05 & 23.68 & 20.77 & 38.32 & 1.755 & 24.29 & 3.51 \\
\hline $\mathrm{Yb}$ & 12.18 & 25.05 & 21.83 & 38.72 & 1.737 & 24.54 & 2.71 \\
\hline $\mathrm{Lu}$ & 13.9 & 20.96 & 19.19 & 38.93 & 1.728 & 24.67 & 5.48 \\
\hline Ac & 11.87 & 18.9 & 17.14 & 33.01 & 2.038 & 20.92 & 3.78 \\
\hline $\mathrm{Th}$ & 11.83 & 20 & 17.96 & 33.81 & 1.990 & 21.43 & 3.47 \\
\hline $\mathrm{Pa}$ & 11.7 & 20 & 17.93 & 34.19 & 1.967 & 21.67 & 3.74 \\
\hline $\mathrm{U}$ & 11.9 & 20 & 17.98 & 34.99 & 1.922 & 22.17 & 4.20 \\
\hline $\mathrm{Np}$ & 11.7 & 20.7 & 18.45 & 35.38 & 1.901 & 22.42 & 3.97 \\
\hline $\mathrm{Pu}$ & 11.7 & 21.8 & 19.28 & 35.77 & 1.881 & 22.67 & 3.39 \\
\hline $\mathrm{Am}$ & 12 & 22.4 & 19.80 & 36.13 & 1.862 & 22.90 & 3.10 \\
\hline $\mathrm{Cm}$ & 12.41 & 21.2 & 19.00 & 36.40 & 1.848 & 23.07 & 4.07 \\
\hline Bk & 12.3 & 22.3 & 19.80 & 36.77 & 1.829 & 23.30 & 3.50 \\
\hline $\mathrm{Cf}$ & 12.5 & 23.6 & 20.83 & 37.03 & 1.817 & 23.47 & 2.64 \\
\hline Es & 12.6 & 24.1 & 21.23 & 37.33 & 1.802 & 23.66 & 2.43 \\
\hline $\mathrm{Fm}$ & 12.7 & 24.4 & 21.48 & 37.63 & 1.788 & 23.85 & 2.37 \\
\hline Md & 12.8 & 25.4 & 22.25 & 37.92 & 1.774 & 24.03 & 1.78 \\
\hline No & 13 & 27 & 23.50 & 38.29 & 1.757 & 24.27 & 0.77 \\
\hline $\mathrm{Lr}$ & 14.8 & 23 & 20.95 & 38.36 & 1.754 & 24.31 & 3.36 \\
\hline
\end{tabular}
radius, $E_{\text {orb }}$ and $E_{\mathrm{des}}$ are the orbital and desolvation energies respectively, and $\Delta H_{\mathrm{h}}$ is the hydration enthalpy 
Table 6 Scale of softness/hardness character for several bases and metal ions $\mathrm{M}_{\mathrm{aq}}{ }^{n+}(n=1-3)$

\begin{tabular}{|c|c|c|c|c|c|}
\hline \multirow{2}{*}{\multicolumn{2}{|c|}{$\frac{s_{\mathrm{b}} / \mathrm{eV}}{\text { Bases }}$}} & \multicolumn{4}{|l|}{$h_{\mathrm{a}} / \mathrm{eV}$} \\
\hline & & \multicolumn{2}{|c|}{ Hard cations } & \multicolumn{2}{|c|}{ Soft cations } \\
\hline $\mathrm{F}^{-}$ & -12.18 & Ga(III) & 1.45 & $\mathrm{Hg}(\mathrm{II})$ & -4.64 \\
\hline $\mathrm{H}_{2} \mathrm{O}$ & -10.73 & $\mathrm{Eu}(\mathrm{III})$ & 1.72 & $\mathrm{Au}(\mathrm{I})$ & -4.35 \\
\hline $\mathrm{OH}^{-}$ & -10.45 & $\mathrm{Ba}(\mathrm{II})$ & 1.89 & Tl(III) & -3.37 \\
\hline $\mathrm{Cl}^{-}$ & -9.94 & $\mathrm{Cr}(\mathrm{III})$ & 2.06 & $\operatorname{Ag}(\mathrm{I})$ & -2.82 \\
\hline $\mathrm{Br}^{-}$ & -9.23 & $\operatorname{Sr}(\mathrm{II})$ & 2.21 & $\mathrm{Cu}(\mathrm{I})$ & -2.30 \\
\hline $\mathrm{CN}^{-}$ & -8.78 & $\mathrm{Fe}(\mathrm{III})$ & 2.23 & $\mathrm{Cd}(\mathrm{II})$ & -2.04 \\
\hline $\mathrm{SH}^{-}$ & -8.59 & $\mathrm{Ca}(\mathrm{II})$ & 2.33 & $\mathrm{Tl}(\mathrm{I})$ & -1.88 \\
\hline \multirow[t]{20}{*}{$\mathrm{I}^{-}$} & -8.31 & Mg(II) & 2.42 & $\mathrm{Cu}(\mathrm{II})$ & -0.55 \\
\hline & & Sm(III) & 2.56 & $\mathrm{Na}(\mathrm{I})$ & 0.00 \\
\hline & & $\mathrm{Yb}(\mathrm{III})$ & 2.71 & Ni(II) & 0.29 \\
\hline & & Am(III) & 3.10 & $\operatorname{Li}(\mathrm{I})$ & 0.49 \\
\hline & & Pm(III) & 3.28 & $\mathrm{Fe}(\mathrm{II})$ & 0.69 \\
\hline & & Nd(III) & 3.32 & $\mathrm{Cr}(\mathrm{II})$ & 0.91 \\
\hline & & $\operatorname{Tm}(\mathrm{III})$ & 3.51 & & \\
\hline & & $\operatorname{Pr}(\mathrm{III})$ & 3.52 & & \\
\hline & & Dy(III) & 3.63 & & \\
\hline & & $\mathrm{Be}(\mathrm{II})$ & 3.75 & & \\
\hline & & Ho(III) & 3.88 & & \\
\hline & & $\mathrm{Cm}$ (III) & 4.07 & & \\
\hline & & $\operatorname{Er}(\mathrm{III})$ & 4.07 & & \\
\hline & & $\mathrm{Ce}(\mathrm{III})$ & 4.20 & & \\
\hline & & $\mathrm{Tb}(\mathrm{III})$ & 4.29 & & \\
\hline & & Ti(IV) & 4.35 & & \\
\hline & & La(III) & 4.60 & & \\
\hline & & Gd(III) & 4.83 & & \\
\hline & & Lu(III) & 5.48 & & \\
\hline & & $\mathrm{Al}(\mathrm{III})$ & 6.01 & & \\
\hline
\end{tabular}

lations are given in Table 5. The values of $R_{\mathrm{s}}$ are derived from experimental values of hydration enthalpies using the BornHaber equation. The ionization potentials of M(III) are taken from ref. 19-21. A classification of bases (in order of increasing softness) and metal ions in order of increasing hardness is shown in Table 6, where the $h_{\mathrm{a}}$ (calculated as described above) of $\mathrm{Ln}$ (III) (in italics), Am(III) and $\mathrm{Cm}$ (III) are included in the series of hard cations.

All trivalent lanthanides appear to be hard acids. However, the values of the lanthanide hardness character range over a rather wide $(3.8 \mathrm{eV})$ interval, from $5.48 \mathrm{eV}$ for $\mathrm{Lu}(\mathrm{III})$ to 1.72 $\mathrm{eV}$ for $\mathrm{Eu}(\mathrm{III})$. This range for the lanthanide hardness character is comparable to that for hard cations $[4.6 \mathrm{eV}$ from $\mathrm{Al}$ (III) to $\mathrm{Ga}(\mathrm{III})]$ and soft cations [5.6 eV from $\mathrm{Cr}$ (II) to $\mathrm{Hg}$ (II)].

The hardness character of $\mathrm{Am}(\mathrm{III})$, at $3.10 \mathrm{eV}$, is comparable to that of $\mathrm{Nd}(\mathrm{III})$ and is significantly higher than that of $\mathrm{Eu}(\mathrm{III})$ $(1.72 \mathrm{eV})$. This result appears to disagree completely with extraction results, which show better extraction of Am(III) than Eu(III) by purified Cyanex 301, which was previously considered as evidence of the softer character of Am(III) compared with $\mathrm{Eu}(\mathrm{III}){ }^{5,22}$ This contradiction is discussed in the next section. Here, based on the extraction results, it can be concluded that the nature of the bonds in the $\mathrm{Am}\left(\mathrm{R}_{2} \mathrm{PSS}\right)_{3}$ complexes approaches those in similar complexes with d-block transition elements. Although the $\mathrm{Ln}-\mathrm{S}$ bond is weaker than the $\mathrm{M}-\mathrm{S}$ bond ( $\mathrm{M}$ being a d-block transition element), the difference is not very significant ${ }^{15}$ for the complexes $\operatorname{Ln}\left(\mathrm{R}_{2} \mathrm{PSS}\right)_{3}$ (where $\left.\mathrm{R}=\mathrm{C}_{6} \mathrm{H}_{11}\right)$ and $\mathrm{Ln}\left(\mathrm{R}_{2} \mathrm{PSS}\right)_{4}$ (where $\mathrm{R}=\mathrm{CH}_{3}, \mathrm{OC}_{2} \mathrm{H}_{5}$ and $\mathrm{C}_{6} \mathrm{H}_{11}$ ).

Fig. 1 shows the hardness trend across the f-block series. Plotted for comparison are the charge transfer energies of: (i) $\mathrm{Cl} \rightarrow 4 \mathrm{f}$ and $\mathrm{Cl} \rightarrow 5 \mathrm{f}$ in the $\left[\mathrm{LnCl}_{6}\right]^{3-}$ and $\left[\mathrm{AnCl}_{6}\right]^{3-}$ compounds, ${ }^{23}$ (ii) $\mathrm{Br} \rightarrow 4 \mathrm{f}$ and $\mathrm{Br} \rightarrow 5 \mathrm{f}$ in the $\left[\mathrm{LnBr}_{6}\right]^{3-}$ and $\left[\mathrm{AnBr}_{6}\right]^{3-}$ compounds $^{23}$ and (iii) $\mathrm{S} \rightarrow 4 \mathrm{f}$ and $\mathrm{S} \rightarrow 5 \mathrm{f}$ in $\mathrm{Ln}\left(\mathrm{R}_{2} \mathrm{PSS}\right)_{3}$ and $\mathrm{An}\left(\mathrm{R}_{2} \mathrm{PSS}\right)_{3}$ (organic phase). ${ }^{8}$

Fig. 1 shows that the trend in Ln(III) hardness character is similar to the trend in charge transfer energy. Although less obvious, a similar conclusion applies to An(III): the trend of $\left(h_{\mathrm{a}}\right)_{\mathrm{An} \text { (III) }}$ with $Z$ is close to those observed for the charge trans-

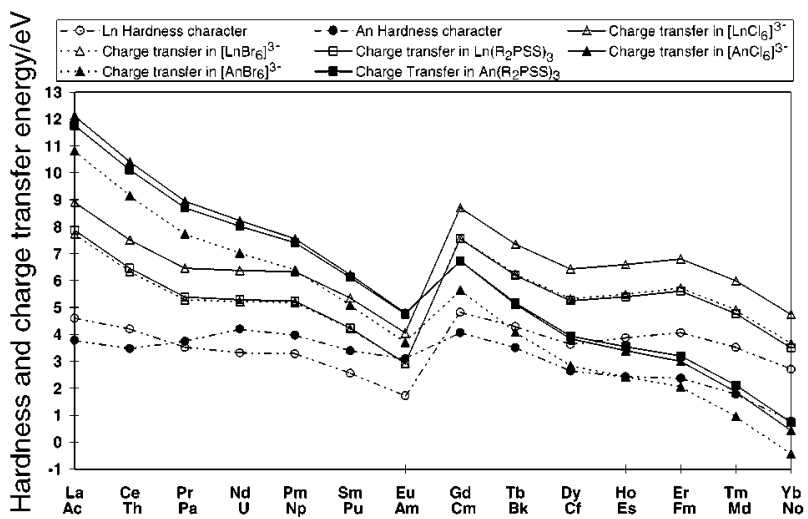

Fig. 1 Comparison of the variation in hardness character $h_{\mathrm{a}}$ of $\mathrm{M}$ (III) ions $(\mathrm{M}=\mathrm{Ln}$ or $\mathrm{An})$ across the $4 \mathrm{f}$ and $5 \mathrm{f}$ series and charge transfer energies in $\left[\mathrm{MX}_{6}\right]^{3-}$ and $\mathrm{M}\left(\mathrm{R}_{2} \mathrm{PSS}\right)_{3}$ complexes.

fer energies $\mathrm{S} \rightarrow 5 \mathrm{f}, \mathrm{Cl} \rightarrow 5 \mathrm{f}$ and $\mathrm{Br} \rightarrow 5 \mathrm{f}$. Moreover, since the charge transfer energies in Ln(III) and An(III) complexes correlate with the corresponding $E_{3 / 2}^{0}$ redox potentials, ${ }^{24}$ the $\operatorname{Ln}(\mathrm{III})$ and $A n(I I I)$ hardness character also correlates with $E_{3 / 2}^{0}$ (Fig. 2). Nevertheless, there are no physical reasons or explanations to accept the value of the charge transfer energy or the redox potential $E_{3 / 2}^{0}$ as a quantitative criterion for covalence in M(III)-L bonds (contrary to Klopman's statements ${ }^{11}$ ). The charge transfer energy $\mathrm{L} \rightarrow 4 \mathrm{f}$ or $5 \mathrm{f}$, and the redox potential $E_{3 / 2}^{0}$, are significant chemical parameters governing the ability of cations to accept electron density $\left[\mathrm{M}^{3+}\left(\mathrm{L}_{3}\right)^{-3} \rightarrow\right.$ $\left.\mathrm{M}^{(3-q)+}\left(\mathrm{L}_{3}\right)^{-3+q}\right]$, but do not fully characterize the hardness of $\operatorname{Ln}(\mathrm{III})$ and $A n(\mathrm{III})$. In principle, a covalent effect can change the hardness character of a cation, such as Am(III), resulting in $\left(h_{\mathrm{a}}\right)_{\mathrm{Am} \text { (III) }} \ll\left(h_{\mathrm{a}}\right)_{\mathrm{Eu}(\mathrm{III})}$ in complexes with the soft base $\mathrm{R}_{2} \mathrm{PSS}^{-}$in the organic phase, as extraction results ${ }^{5}$ have demonstrated.

The main aim of the present paper is to compare the An(III) and Ln(III) coordination extraction mechanisms by investigating the extraction of $\mathrm{Am}$ (III) and Eu(III) using a synergistic mixture of $(\mathrm{Cl} \Phi)_{2} \mathrm{PSSH}$ with a neutral organophosphorus compound bearing hard oxygen donor atoms. ${ }^{7}$ In this regard, from the standpoint of base softness, $(\mathrm{Cl} \Phi)_{2} \mathrm{PSSH}$ appears to be a weaker extractant than $\mathrm{R}_{2} \mathrm{PSSH}$ and the two mechanisms of extraction may be: (i) completely different, (ii) significantly modified or even (iii) similar. To the best of our knowledge, the first complexes of diphenyldithiophosphinic acid [an extractant with similar chemical properties to $\left.(\mathrm{Cl} \Phi)_{2} \mathrm{PSSH}\right]$ were prepared with the $\mathrm{d}$ transition elements $\mathrm{Cr}$ (III) (hard cation with $h_{\mathrm{a}}=2.06 \mathrm{eV}$ ) and $\mathrm{Ni}$ (II) (soft cation with $\left.h_{\mathrm{a}}=0.29 \mathrm{eV}\right) .{ }^{25}$ We can therefore expect $\mathrm{Eu}(\mathrm{III})$ and Am(III), having different hardness character, to form complexes with $(\mathrm{Cl} \Phi)_{2} \mathrm{PSSH}$, which may be strengthened by donoracceptor interactions with the hard $\mathrm{O}$ donor atom through electron density redistribution in the system: $\mathrm{O} \rightarrow \mathrm{M}(\mathrm{III}) \rightarrow \mathrm{S}$.

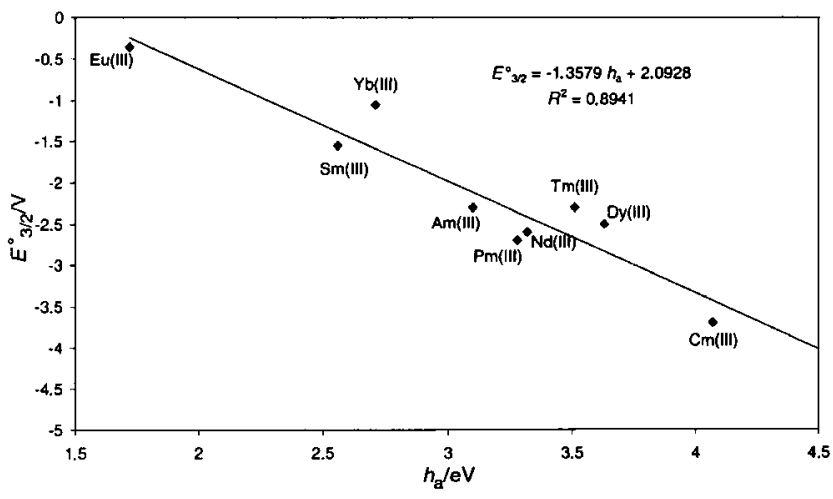

Fig. 2 Correlation between redox potentials $E_{3 / 2}^{0}$ and the corresponding hardness character $h_{\mathrm{a}}$ of $\mathrm{M}(\mathrm{III})(\mathrm{M}=\mathrm{Ln}$ and An) cations. 


\section{Experimental data base and scope of anticipated problems}

An analysis of the experimental data presented in Table 2 raises problems that must be solved to interpret the synergistic effect on the extractability of $\mathrm{Am}$ (III) and $\mathrm{Eu}(\mathrm{III})$. Accordingly, some co-extractants B were classified into two groups.

Group 1: TBP and TBPO; TOP and TOPO; T2EHP and BPOPO. The first class of co-extractants B shows a simple and clear regularity for the extractability of $\mathrm{Am}(\mathrm{III})$ and $\mathrm{Eu}(\mathrm{III})$. Extractability with TBP is less than with TBPO, since the O atom is a weaker donor in the former co-extractant than in the latter. In fact, the low electron affinity of the butyl group in TBPO induces a high basicity in the $\mathrm{O}$ atom and thus a strong synergistic effect. Conversely, the high electron affinity of the butyl-O group in TBP induces a low basicity in the $\mathrm{O}$ atom, and hence a weak synergistic effect.

In the extraction of $\mathrm{Am}$ (III) and $\mathrm{Eu}(\mathrm{III})$ from $2.0 \mathrm{M}$ $\mathrm{LiNO}_{3}-0.01 \mathrm{M} \mathrm{HNO}_{3}$ by $0.25 \mathrm{M}$ TBP or TBPO, ${ }^{26} \mathrm{SF}_{\mathrm{Am} / \mathrm{Eu}}$ was found to be $<1$, whereas extraction with $(\mathrm{Cl} \Phi)_{2} \mathrm{PSSH}$ + TBP or TBPO gave greater selectivity $\left(\mathrm{SF}_{\mathrm{Am} / \mathrm{Eu}} \gg 1\right)$. Hence, the questions arising for this first class of coextractants are: does Am(III) form stronger complexes with $(\mathrm{Cl} \Phi)_{2} \mathrm{PSSH}$ than $\mathrm{Eu}(\mathrm{III})$, and is the selectivity due to the effect of stronger $\mathrm{Am}-\mathrm{S}$ bonds in comparison with $\mathrm{Eu}-\mathrm{S}$ bonds or to the net synergistic effect, or both?

In the case of $\mathrm{Am}(\mathrm{III})$ and $\mathrm{Eu}(\mathrm{III})$ extraction with the synergistic mixture Cyanex $301+\mathrm{TOPO}^{5}{ }^{5}$ the $\mathrm{SF}_{\mathrm{Am} / \mathrm{Eu}}$ is again $<1$, similar to what is observed for the complexes $\mathrm{M}\left(\mathrm{NO}_{3}\right)_{3} \cdot n \mathrm{TOPO}$, where no $\mathrm{M}-\mathrm{S}$ bond is formed. The main difference between the two extractants, Cyanex $301\left(\mathrm{R}_{2} \mathrm{PSSH}\right)$ and $(\mathrm{Cl} \Phi)_{2} \mathrm{PSSH}$, thus concerns their different $\mathrm{Am} / \mathrm{Eu}$ selectivity, when employed in synergistic combinations with the same co-extractants B, TBP and TOPO. For the two branched phosphate and phosphine oxide co-extractants, T2EHP and BPOPO respectively, the extractability of Am(III) is greater than that of Eu(III), but the selectivity is greater for T2EHP.

Group 2: TOP, T2EHP and TOPO. The higher selectivity observed with T2EHP demands a theoretical explanation.

\section{Synergistic effect in the systems $\mathrm{M}(\mathrm{III}) /(\mathrm{Cl \Phi})_{2} \mathrm{PSSH} / \mathrm{B}$}

The synergistic effect can be evaluated by considering the ratio of the distribution ratios for the extraction of $\mathrm{M}$ (III) by synergistic mixtures and by $(\mathrm{Cl} \Phi)_{2} \mathrm{PSSH}$ alone. Thus:

$$
\Delta_{\mathbf{M}}^{\mathrm{syn}}(\mathrm{B})=\log D_{\mathbf{M} /(\mathrm{C} \mid \Phi)_{2} \mathbf{P S S H} / \mathbf{B}}-\log D_{\mathbf{M} /(\mathrm{Cl} \Phi)_{2} \mathbf{P S S H}}
$$

To be able to calculate $\Delta_{\mathrm{M}}^{\mathrm{syn}}(\mathrm{B}), D_{\mathbf{M} /(\mathrm{Cl} \Phi)_{2} \mathrm{PsSH}}$ must be evaluated for the extraction with $(\mathrm{Cl} \Phi)_{2} \mathrm{PSSH}$ alone, because these data

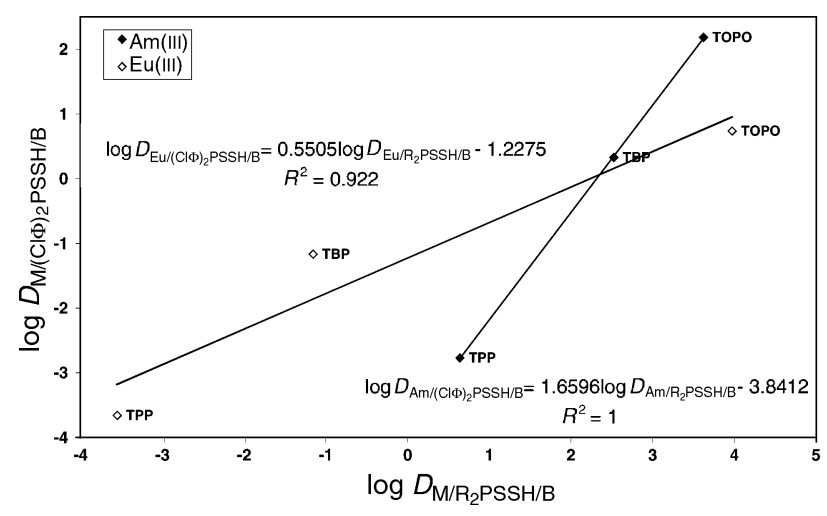

Fig. 3 Correlation between $\log D_{\mathrm{M} / \mathrm{R}_{2} \mathrm{PSSH} / \mathrm{B}}$ corresponding to the extraction of Am(III) and $\mathrm{Eu}(\mathrm{III})$ by Cyanex $301+\mathrm{B}$ systems ${ }^{5}$ and $\log$ $D_{\mathrm{M} /(\mathrm{Cl} \Phi)_{2} \mathrm{PSSH} / \mathrm{B}}$ with three common co-extractants: TPP, TBP and TOPO. were not determined experimentally at similar $\mathrm{pH}$ values. This will be done in the following.

The data on the extraction of Am(III) and Eu(III) by the two sets of synergistic systems Cyanex $301\left(\mathrm{R}_{2} \mathrm{PSSH}\right)+\mathrm{B}^{5}$ and $(\mathrm{Cl \Phi})_{2} \mathrm{PSSH}+\mathrm{B}$ (Table 2) refer to three common coextractants (TBP, TOPO and TPP). Fig. 3 shows that the extractability of $\mathrm{Am}$ (III) and $\mathrm{Eu}(\mathrm{III})$ are linearly related in $\log -\log$ plots of the two systems using these co-extractants. On the other hand, the extractability of Am(III) and Eu(III) in the absence of B is known for $\mathrm{R}_{2} \mathrm{PSSH} .{ }^{5}$ With these two series of data, and from the linear relationships of Fig. 3, the distribution ratios can thus be calculated for the extraction of $\mathrm{Am}(\mathrm{III})$ and $\mathrm{Eu}(\mathrm{III})$ by $(\mathrm{Cl} \Phi)_{2}$ PSSH. The following results were obtained for the experimental conditions given in Table 2: $\log$ $D_{\mathrm{Am} /(\mathrm{Cl} \Phi)_{2} \mathrm{PSSH}}=-2.31$ (i.e. $\left.D_{\mathrm{Am} /(\mathrm{Cl} \Phi)_{2} \mathrm{PSSH}}=0.0049\right)$ and $\log$ $D_{\mathrm{Eu} /(\mathrm{Cl} \Phi)_{2} \mathrm{PSSH}}=-2.65$ (i.e. $D_{\mathrm{Eu} /(\mathrm{Cl} \Phi)_{2} \mathrm{PSSH}}=0.0023$ ). These data show that, in these experimental conditions, the affinity of $(\mathrm{Cl \Phi})_{2} \mathrm{PSSH}$ for $\mathrm{Am}$ (III) and $\mathrm{Eu}(\mathrm{III})$ is rather weak.

In the case of the extracted complexes $\mathrm{M}\left(\mathrm{NO}_{3}\right)_{3} \mathrm{~B}_{3},{ }^{26}$ an excellent linear correlation is observed between $\log D_{\text {Am(III) }}$ and $\log D_{\mathrm{Eu}(\mathrm{III})}$, but there is almost no selectivity in the extraction [Fig. 4(a)]. In the extraction of $\mathrm{Am}(\mathrm{III})$ and $\mathrm{Eu}(\mathrm{III})$ by Cyanex $301+\mathrm{B}$ synergistic mixtures, a poor correlation is observed between the extractabilities of the two metal ions [Fig. 4(b)], although good selectivity $\left(\mathrm{SF}_{\mathrm{Am} / \mathrm{Eu}}\right)$ is observed for $\mathrm{B}=\mathrm{TPP}, \mathrm{T} t \mathrm{BP}$ and D2EHDMBA, for which the extractability of Am(III) seems frozen while that of Eu(III) varies sharply. In the extraction of $\mathrm{Am}(\mathrm{III})$ and $\mathrm{Eu}(\mathrm{III})$ by $(\mathrm{Cl} \Phi)_{2} \mathrm{PSSH}$ $+\mathrm{B}$ synergistic mixtures, two co-extractants (TOP and T2EHP) do not enter in the correlation between the extractabilities of the two M(III) ions [Fig. 4(c)]. Without these coextractants, the correlation coefficient would be very good $\left(R^{2}=0.99\right)$. From these facts, it follows that a high selectivity between Am(III) and Eu(III) means a strong synergistic effect for Am(III) complexes and/or a strong antagonistic effect for Eu(III) complexes.

Table 7 shows the values of the synergistic effects $\Delta_{\mathbf{M}}^{\mathrm{syn}}(\mathrm{B})$ for the extraction of $\mathrm{Am}(\mathrm{III})$ and $\mathrm{Eu}(\mathrm{III})$ by $(\mathrm{Cl} \Phi)_{2} \mathrm{PSSH}+\mathrm{B}$ mixtures, calculated according to eqn. (4). The data in Table 7 support the following qualitative considerations: the synergistic effect depends on the cation complexation with extractants and on the compatibility of the donor atoms in B and the S-bearing extractants.

Fig. 5 shows the difference in the synergistic effects for $\mathrm{Am}$ (III) and $\mathrm{Eu}(\mathrm{III})\left[\Delta_{\mathrm{Am} / \mathrm{Eu}}^{\mathrm{syn}}(\mathrm{B})=\Delta_{\mathrm{Am}}^{\mathrm{syn}}(\mathrm{B})-\Delta_{\mathrm{Eu}}^{\mathrm{syn}}(\mathrm{B})\right]$ for various $\mathrm{B}$, along with the observed experimental selectivity $\mathrm{SF}_{\mathrm{Am} / \mathrm{Eu}}{ }^{8}$ The following conclusions can be drawn from Table 7 and Fig. 5. (i) Although the synergistic effects for Am(III) and Eu(III) change irregularly on the scale of increasing selectivity (i.e. from TPP to T2EHP), the difference in synergistic effects for the two metals $\left[\Delta_{\mathrm{Am} / \mathrm{Eu}}^{\mathrm{syn}}(\mathrm{B})\right]$ appears to be a monotonic function of the selectivity (these values only differ by the constant value $\left.\log D_{\mathrm{Am} /(\mathrm{Cl})_{2} \mathrm{PSSH}}-\log \quad D_{\mathrm{Eu} /(\mathrm{Cl})_{2} \mathrm{PSSH}}\right)$. (ii) When

Table 7 Synergistic effect $\Delta_{\mathrm{M}}^{\mathrm{syn}}(\mathrm{B})$ in the reaction $\mathrm{M} /(\mathrm{Cl} \Phi)_{2} \mathrm{PSSH}$ $+\mathrm{B} \leftrightarrow \mathrm{M} /(\mathrm{Cl} \Phi)_{2} \mathrm{PSSH} / \mathrm{B}$

\begin{tabular}{lrrl}
\hline B & $\Delta_{\mathrm{Am}}^{\text {syn }}(\mathrm{B})$ & \multicolumn{1}{c}{$\Delta_{\mathrm{Eu}}^{\text {syn }}(\mathrm{B})$} & Comments \\
\hline TMP & -0.03 & -0.78 & Decrease, Am $<\mathrm{Eu}$ \\
TBP & 2.64 & 1.48 & Increase, Am $>\mathrm{Eu}$ \\
THP & 2.51 & 1.17 & Increase, Am $>\mathrm{Eu}$ \\
TOP & 2.34 & -0.17 & Increase, Am \\
T2EHP & 2.42 & -0.27 & Increase, Am \\
TPP & -0.46 & -1.01 & Decrease, Am $<\mathrm{Eu}$ \\
TAP & 1.99 & 0.82 & Increase, Am $>\mathrm{Eu}$ \\
TBPO & 4.19 & 3.27 & Increase, Am $>\mathrm{Eu}$ \\
TOPO & 4.49 & 3.39 & Increase, Am $>\mathrm{Eu}$ \\
TPPO & 4.15 & 2.91 & Increase, Am $>\mathrm{Eu}$ \\
BPOPO & 2.55 & 1.49 & Increase, Am $>\mathrm{Eu}$ \\
TiBPS & 0.61 & -0.05 & Increase Am \\
\end{tabular}



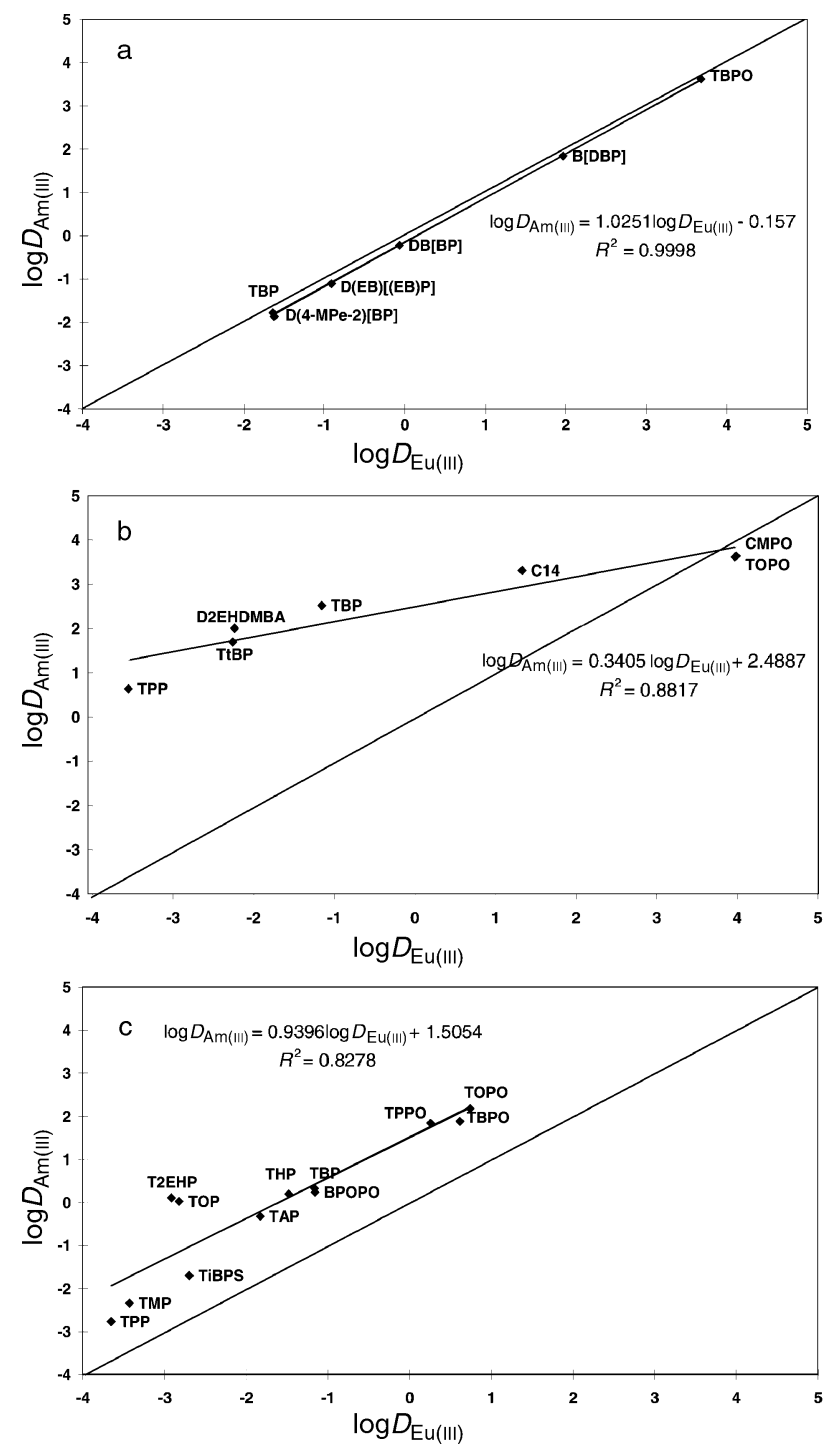

Fig. 4 Three correlations between the extractability of $A m($ III) and $\mathrm{Eu}(\mathrm{III})$ : (a) $\mathrm{M}$ (III) $/ \mathrm{NO}_{3} / \mathrm{B}$ extracted complexes; ${ }^{29}$ (b) $\mathrm{M}$ (III) $/ \mathrm{R}_{2} \mathrm{PSSH} / \mathrm{B}$ extracted complexes; ${ }^{5}$ (c) $\mathrm{M}(\mathrm{III}) /(\mathrm{Cl} \Phi)_{2} \mathrm{PSSH} / \mathrm{B}$ extracted complexes. ${ }^{7}$ The lines between the data points correspond to the least squares adjustments of the data and the diagonal lines correspond to log $D_{\mathrm{Am}(\mathrm{III})}=\log D_{\mathrm{Eu}(\mathrm{III})}$, that is $\mathrm{SF}_{\mathrm{Am} / \mathrm{Eu}}=1$.

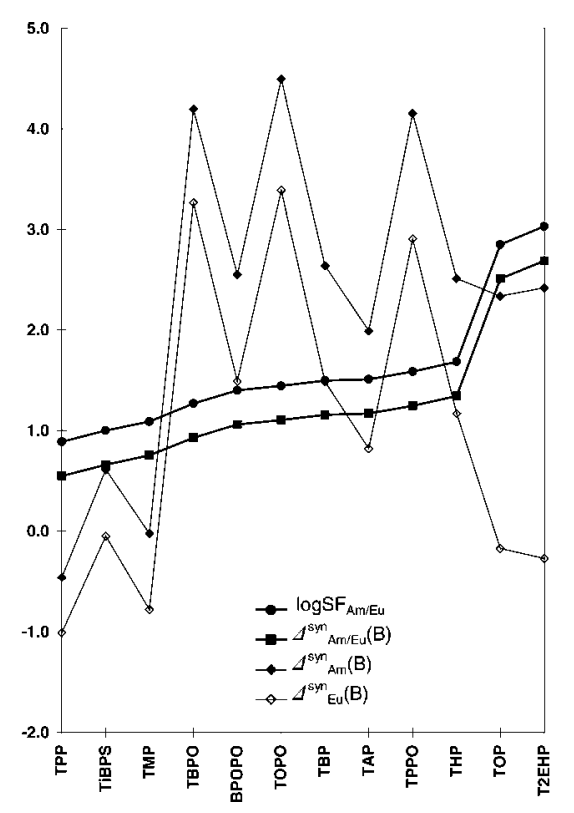

Fig. 5 Comparison of synergistic effect and selectivity in $\mathrm{M} /(\mathrm{Cl} \Phi)_{2} \mathrm{PSSH} / \mathrm{B}$ systems for twelve co-extractants B.
$\Delta_{\mathbf{M}}^{\mathrm{syn}}(\mathrm{B}) \geqslant 0$, the synergistic effects are bonding, that is the coextractants B promote the formation of $\mathrm{M}-\mathrm{S}$ bonds. The synergistic bonding effect is stronger for complexes of Am(III) than for those of Eu(III). This effect, added to a slightly better extraction of $\mathrm{Am}(\mathrm{III})$ than $\mathrm{Eu}(\mathrm{III})$ by $(\mathrm{Cl} \Phi)_{2} \mathrm{PSSH}$, results in the good selectivity $\mathrm{SF}_{\mathrm{Am} / \mathrm{Eu}}$. (iii) When $\Delta_{\mathrm{M}}^{\mathrm{syn}}(\mathrm{B})<0$, an antagonistic effect occurs. It is stronger for complexes of $\mathrm{Eu}(\mathrm{III})$ than for those of Am(III); as usual in the theory of the chemical bond, the bonding effect is more effective in promoting bonds than the antibonding effect is in preventing bond formation. (iv) The high selectivity observed using T2EHP and TOP is caused by a bonding effect for Am(III) and an antibonding effect for Eu(III). (v) In the case of phosphine oxides such as TBPO, TOPO and TPPO, strong synergistic effects are observed for both cations and $\Delta_{\mathrm{Am}}^{\mathrm{syn}}(\mathrm{B})>\Delta_{\mathrm{Eu}}^{\mathrm{syn}}(\mathrm{B})$ by approximately one logarithmic unit. The branched phosphine oxide, BPOPO, has a lower synergistic effect, but exhibits almost the same selectivity as the others. (vi) Finally, the soft coextractant, TiBPS, in combination with the soft $(\mathrm{Cl} \Phi)_{2} \mathrm{PSSH}$ acid, shows almost no synergistic effect for the complexation of $\mathrm{Eu}(\mathrm{III})$ and a weak one for Am(III). The selectivity is accordingly low.

In the first paper of this series, ${ }^{8}$ the interrelation between the interatomic distances $R_{\mathrm{Eu}-\mathrm{S}}$ and $R_{\mathrm{Eu}-\mathrm{O}}$ and the shifts in charge transfer energy $\mathrm{S} \rightarrow \mathrm{Eu}(\mathrm{III})$ in $\mathrm{Eu} / \mathrm{R}_{2} \mathrm{PSSH} / \mathrm{B}$ complexes was shown to depend on the donor ability of the coextractants: for strong donors, decreasing $R_{\mathrm{Eu}-\mathrm{O}}$ corresponds to increasing $R_{\mathrm{Eu}-\mathrm{S}}$ and charge transfer energy $E(\mathrm{~S} \rightarrow \mathrm{Eu})$ while for weak donors, increasing $R_{\mathrm{Eu}-\mathrm{O}}$ corresponds to decreasing $R_{\mathrm{Eu}-\mathrm{S}}$ and $E(\mathrm{~S} \rightarrow \mathrm{Eu})$.

In the case of $\mathrm{Eu} /(\mathrm{Cl} \Phi)_{2} \mathrm{PSSH} / \mathrm{B}$ complexes, the interpretation of the absorption spectra presents difficulties: the bands are broad because of a strong coupling with phonons. Fortunately, however, the trend in $E(\mathrm{~S} \rightarrow \mathrm{Eu})$ for $\mathrm{Eu} /(\mathrm{Cl} \Phi)_{2} \mathrm{PSSH} / \mathrm{B}$ and $\mathrm{Eu} / \mathrm{R}_{2} \mathrm{PSSH} / \mathrm{B}$ complexes with $\mathrm{B}=\mathrm{TPP}, \mathrm{TBP}$ and TOPO is the same, although the absolute values of $E(\mathrm{~S} \rightarrow \mathrm{Eu})$ differ. This trend may be interpreted if we consider that a single co-extractant induces the same type of synergistic effect with both S-bearing extractants.

In ref. 8, the interatomic distances $R_{\mathrm{Eu}-\mathrm{S}}$ in $\mathrm{Eu} / \mathrm{R}_{2} \mathrm{PSSH} / \mathrm{B}$ complexes were calculated from the charge transfer energy $E(\mathrm{~S} \rightarrow \mathrm{Eu})$ in these complexes and an equation was developed connecting $R_{\mathrm{Eu}-\mathrm{S}}$ with $\Delta_{\mathrm{Eu}}^{\mathrm{syn}}(\mathrm{B})$ :

$$
\Delta_{\mathrm{Eu}}^{\mathrm{syn}}(\mathrm{B})=a \times\left[R_{\mathrm{Eu}-\mathrm{S}}\right]^{2}+b \times R_{\mathrm{Eu}-\mathrm{S}}+c
$$

where constants $a=-110.13, b=710.43$ and $c=-1139.1$.

Keeping in mind the same trend in $E(\mathrm{~S} \rightarrow \mathrm{Eu})$ in both $\mathrm{Eu} /(\mathrm{Cl} \Phi)_{2} \mathrm{PSSH} / \mathrm{B}$ and $\mathrm{Eu} / \mathrm{R}_{2} \mathrm{PSSH} / \mathrm{B}$ complexes, we can use

Table $8 A_{\mathrm{Eu}}^{\mathrm{syn}}(\mathrm{B})$ and interatomic $R_{\mathrm{Eu}-\mathrm{S}}$ distances in $\mathrm{Eu} /(\mathrm{Cl} \Phi)_{2}$ $\mathrm{PSSH} / \mathrm{B}$ and $\mathrm{Eu} / \mathrm{R}_{2} \mathrm{PSSH} / \mathrm{B}$ complexes ${ }^{8}$

\begin{tabular}{|c|c|c|c|c|}
\hline \multirow[b]{2}{*}{ B } & \multicolumn{2}{|c|}{$(\mathrm{Cl} \Phi)_{2} \mathrm{PSSH}$} & \multicolumn{2}{|c|}{$\mathrm{R}_{2} \mathrm{PSSH}$} \\
\hline & $\Delta_{\mathrm{Eu}}^{\mathrm{syn}}(\mathrm{B})$ & $R_{\mathrm{Eu}-\mathrm{S}} / \AA$ & $\Delta_{\mathrm{Eu}}^{\text {syn }}(\mathrm{B})$ & $R_{\mathrm{Eu}-\mathrm{S}} / \AA$ \\
\hline ТВP & 1.48 & 3.01 & 1.43 & 3.00 \\
\hline TPP & -1.01 & 2.96 & -0.97 & 2.96 \\
\hline TOPO & 3.39 & 3.05 & 6.55 & 3.25 \\
\hline TMP & -0.78 & 2.97 & & \\
\hline THP & 1.17 & 3.00 & & \\
\hline TOP & -0.17 & 2.98 & & \\
\hline T2EHP & -0.27 & 2.98 & & \\
\hline TAP & 0.82 & 3.00 & & \\
\hline ТВРО & 3.27 & 3.05 & & \\
\hline ВРOPO & 1.49 & 3.01 & & \\
\hline ТРPO & 2.91 & 3.04 & & \\
\hline TiBPS & -0.05 & 2.98 & & \\
\hline $\mathrm{T} t \mathrm{BP}$ & & & 0.32 & 2.98 \\
\hline DOTA & & & 0.35 & 2.98 \\
\hline $\mathrm{C} 14$ & & & 3.91 & 3.07 \\
\hline CMPO & & & 6.57 & 3.25 \\
\hline
\end{tabular}


eqn. (5) to evaluate the $R_{\mathrm{Eu}-\mathrm{S}}$ distances with the $\Delta_{\mathrm{Eu}}^{\mathrm{syn}}(\mathrm{B})$ given in Table 7 for $\mathrm{Eu} /(\mathrm{Cl} \Phi)_{2} \mathrm{PSSH} / \mathrm{B}$ complexes. The calculated $R_{\mathrm{Eu}-\mathrm{S}}$ values and those in $\mathrm{Eu} / \mathrm{R}_{2} \mathrm{PSSH} / \mathrm{B}$ for comparison are given in Table 8 , together with $\Delta_{\mathrm{Eu}}^{\mathrm{syn}}(\mathrm{B})$. The following conclusions can be drawn. In $\mathrm{Eu} /(\mathrm{Cl} \Phi)_{2} \mathrm{PSSH} / \mathrm{TOPO}$ complexes, the co-extractant TOPO does not possess as high a donor ability as in $\mathrm{Eu} / \mathrm{R}_{2} \mathrm{PSSH} / \mathrm{TOPO}$; the effect of TOPO on $R_{\mathrm{Eu}-\mathrm{S}}$ is therefore less. In $\mathrm{Eu} /(\mathrm{Cl} \Phi)_{2} \mathrm{PSSH} / \mathrm{B}$ complexes no coextractant which is as strong a donor as CMPO was used in the extraction with Cyanex 301 ; as a result, no $R_{\mathrm{Eu}-\mathrm{S}}$ as long as $3.25 \AA$ was obtained. The range of $R_{\mathrm{Eu}-\mathrm{S}}$ distances is determined by the synergistic effect: it is narrower for $\mathrm{Eu} /(\mathrm{Cl} \Phi)_{2} \mathrm{PSSH} / \mathrm{B}$ complexes $\left(3.05>R_{\mathrm{Eu}-\mathrm{S}}>2.96 \AA\right)$ than for $\mathrm{Eu} / \mathrm{R}_{2} \mathrm{PSSH} / \mathrm{B}$ complexes $\left(3.25>R_{\mathrm{Eu}-\mathrm{S}}>2.96 \AA\right)$.

Moreover, the $\mathrm{Eu}-\mathrm{S}$ distance in the $\mathrm{Eu}(\mathrm{Cl} \Phi)_{2} \mathrm{PSSH}$ complex without a co-extractant was roughly evaluated from the correlation between $R_{\mathrm{Eu}-\mathrm{S}}$ and $E(\mathrm{~S} \rightarrow \mathrm{Eu})$ (Fig. 6), where $\mathrm{B}=$ TPP, TBP and TOPO. From the plot, we find that $R_{\mathrm{Eu}-\mathrm{S}}=2.97 \AA$. If we compare this value with the $R_{\mathrm{Eu}-\mathrm{S}}$ value of $3.03 \AA$ obtained for Eu/ $\mathrm{R}_{2}$ PSSH complexes, ${ }^{8}$ and taking account of the estimated $\pm 0.05 \AA$ uncertainty, we can conclude that these distances are the same.

In our previous paper, we studied the mechanism of the synergistic effect in the extraction of $\mathrm{Am}$ (III) and $\mathrm{Eu}(\mathrm{III})$ by $\mathrm{R}_{2}$ PSSH (Cyanex 301). ${ }^{8}$ In this section, the synergistic effects

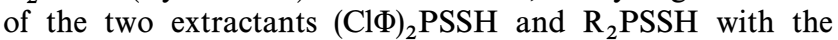
common co-extractants TBP, TPP and TOPO are compared in Fig. 7, which shows an antagonist effect with TPP $\left(\Delta_{\mathbf{M}}^{\text {syn }}<\right.$ $0)$ and synergistic effects with TBP and $\operatorname{TOPO}\left(\Delta_{\mathbf{M}}^{\text {syn }}>0\right)$.

Antagonistic effects of TPP. Two main mechanisms can be considered for the antagonist synergistic effects observed with TPP: steric incompatibility of the soft donor atoms $\mathrm{S}$ of acidic S-bearing extractants and the hard $\mathrm{O}$ atom of $\mathrm{B}$ in the

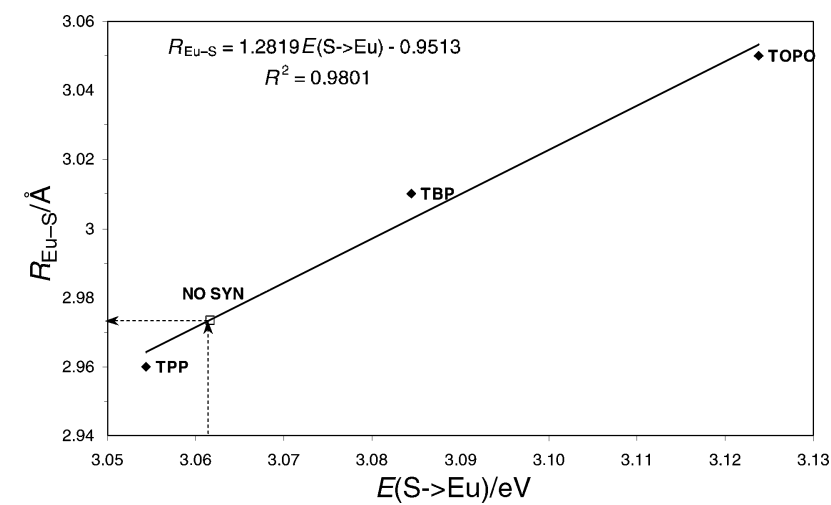

Fig. 6 Correlation between $E(\mathrm{~S} \rightarrow \mathrm{Eu})$ charge transfer energy and $\mathrm{Eu}-\mathrm{S}$ distances in $\mathrm{Eu} /(\mathrm{Cl} \Phi)_{2} \mathrm{PSSH} / \mathrm{B}$ complexes. The $R_{\mathrm{Eu}-\mathrm{S}}$ value in the complex without $\mathrm{B}$ is inferred from the correlation.

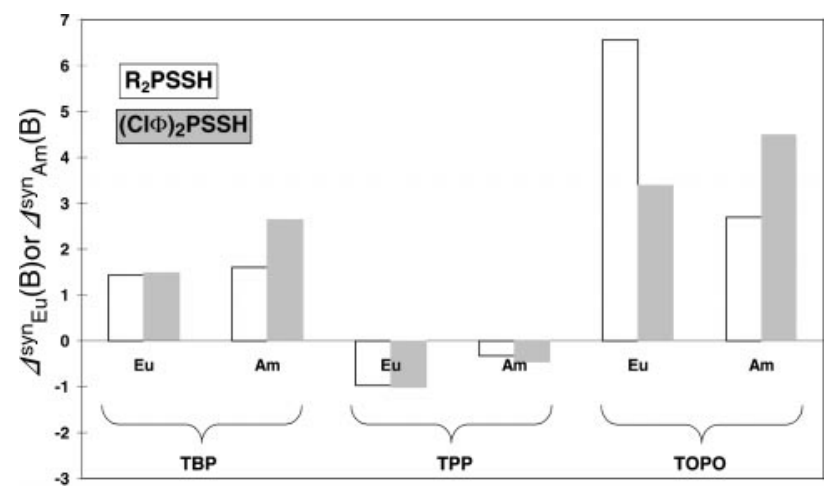

Fig. 7 Comparison of synergistic effects for $\mathrm{R}_{2} \mathrm{PSSH}$ and $(\mathrm{Cl} \Phi)_{2}$ PSSH for three common co-extractants (TBP, TPP and TOPO).
M(III) coordination polyhedra, and coordination incompatibility of soft and hard donor atoms in the S-bearing extractant and co-extractant respectively, resulting in decreasing basicity of the soft donor atoms $\mathrm{S}$ caused by back electron transfer: soft donor $\rightarrow$ cation $\rightarrow$ hard donor.

In the case of TPP, with both $(\mathrm{Cl} \Phi)_{2} \mathrm{PSSH}$ and $\mathrm{R}_{2} \mathrm{PSSH}$ extractants, the antagonistic effect could stem from the steric effect arising from the relative arrangement of the phenyl groups of TPP. It is greater for complexes of Eu(III) than for those of Am(III), undoubtedly because Eu(III) has a smaller ionic radius than Am(III), but the synergistic effects are similar for both systems $\left[\Delta_{\mathrm{Am}}^{\mathrm{syn}}(\mathrm{B})\right.$ equal to -0.46 for $(\mathrm{Cl} \Phi)_{2} \mathrm{PSSH}$ and -0.28 for $\mathrm{R}_{2}$ PSSH systems]. Moreover, the values of $\Delta_{\mathrm{Eu}}^{\mathrm{syn}}(\mathrm{B})$ are roughly the same $(\approx-1.0)$ for the Eu(III) complexes for both systems. It is thus clearly acceptable to find $R_{\mathrm{Eu}-\mathrm{S}} 2.96 \AA$ for both systems in Table 8 . The high selectivity $\mathrm{SF}_{\mathrm{Am} / \mathrm{Eu}}$ observed for the $\mathrm{R}_{2} \mathrm{PSSH}+\mathrm{TPP}$ mixture $^{8}$ is obtained by good complexation of Am(III) with $\mathrm{R}_{2} \mathrm{PSSH}$ and the antagonistic effect of TPP in $\mathrm{Eu} / \mathrm{R}_{2} \mathrm{PSSH} / \mathrm{TPP}$ complexes. On the contrary, selectivity is low with the $(\mathrm{Cl} \Phi)_{2} \mathrm{PSSH}+\mathrm{TPP}$ mixture (see Table 2) because of the weak complexation of $\mathrm{Am}(\mathrm{III})$ with $(\mathrm{Cl} \Phi)_{2} \mathrm{PSSH}$.

Synergistic effects of TBP. The extractability of Eu(III) and synergistic effects $\Delta_{\mathrm{Eu}}^{\mathrm{syn}}(\mathrm{TBP})$ with $(\mathrm{Cl} \Phi)_{2} \mathrm{PSSH}$ and $\mathrm{R}_{2} \mathrm{PSSH}$ are approximately the same. However, the synergistic effect for $\mathrm{Am} /(\mathrm{Cl} \Phi)_{2} \mathrm{PSSH}$ complex(es) is higher $\left[\Delta_{\mathrm{Am}}^{\mathrm{syn}}(\mathrm{TBP})=2.64\right]$ than for $\mathrm{Am} / \mathrm{R}_{2} \mathrm{PSSH}$ complex(es) $\left[\Delta_{\mathrm{Am}}^{\text {syn }}(\mathrm{TBP})=1.60\right]$. The mechanism of the synergistic effect is thought to be the same for both extractant systems and once again, the difference in $\mathrm{SF}$ is mainly due to good complexation of Am(III) with $\mathrm{R}_{2} \mathrm{PSSH}$ and to poor complexation with $(\mathrm{Cl} \Phi)_{2} \mathrm{PSSH}$. As far as Eu(III) is concerned, the distance $R_{\mathrm{Eu}-\mathrm{S}}=3.0 \AA$ is the same in both $\mathrm{Eu} /(\mathrm{Cl} \Phi)_{2} \mathrm{PSSH} / \mathrm{TBP}$ and $\mathrm{Eu} / \mathrm{R}_{2} \mathrm{PSSH} / \mathrm{TBP}$ complexes since the $\Delta_{\mathrm{Eu}}^{\text {syn }}(\mathrm{TBP})$ values are very close for both systems.

Synergistic effects of TOPO. The synergistic effect for both extractants and both $\mathrm{M}(\mathrm{III})$ cations are strong but $\Delta_{\mathrm{Eu}}^{\mathrm{syn}}(\mathrm{TOPO})=6.55>\Delta_{\mathrm{Am}}^{\mathrm{syn}}(\mathrm{TOPO})=2.70$ with $\mathrm{R}_{2} \mathrm{PSSH}$, while $\quad \Delta_{\mathrm{Eu}}^{\mathrm{syn}}(\mathrm{TOPO})=3.39<\Delta_{\mathrm{Am}}^{\text {syn }}(\mathrm{TOPO})=4.49$ for $(\mathrm{Cl} \Phi)_{2} \mathrm{PSSH}$. The synergistic effects thus differ sharply for the two extraction systems. From the calculations in Table 8, a distance $R_{\mathrm{Eu}-\mathrm{S}}=3.05 \AA$ was obtained in the $\mathrm{Eu} /(\mathrm{Cl} \Phi)_{2} \mathrm{PSSH} / \mathrm{TOPO}$ complex showing that $R_{\mathrm{Eu}-\mathrm{S}}^{(\mathrm{Cl} \Phi)_{2} \mathrm{PSSH}}<$ $R_{\mathrm{Eu}-\mathrm{S}}^{\mathrm{R}_{2} \mathrm{PSSH}}$. It thus appears that the Eu $\mathrm{R}_{2} \mathrm{PSSH}$ TOPO complex is stable mainly owing to the existence of the strong $\mathrm{Eu}-$ $\mathrm{O}(\mathrm{TOPO})$ bond, whereas $\mathrm{Eu} /(\mathrm{Cl} \Phi)_{2} \mathrm{PSSH} / \mathrm{TOPO}$ is stable mainly due to the presence of Eu-S bonds.

The selectivity $\mathrm{SF}_{\mathrm{Am} / \mathrm{Eu}}<1$ of the extraction by $\mathrm{R}_{2} \mathrm{PSSH}$ + TOPO also shows that the nitrate anion can participate in $\mathrm{M}$ (III) complex formation. The long $\mathrm{Eu}-\mathrm{S}$ distance and weak complexation with $\mathrm{R}_{2} \mathrm{PSSH}$, but the strong complexation of M(III) with TOPO (and possibly with $\mathrm{NO}_{3}{ }^{-}$) are the main reasons why $\mathrm{SF}_{\mathrm{Am} / \mathrm{Eu}}<1$ for two complexes as different as $\mathrm{M}\left(\mathrm{NO}_{3}\right)_{3}(\mathrm{TOPO})_{3}$ and $\mathrm{M} / \mathrm{R}_{2} \mathrm{PSSH} / \mathrm{TOPO}$. Conversely, the selectivity ratio $\mathrm{SF}_{\mathrm{Am} / \mathrm{Eu}}$ is $\gg 1$ for $\left.\mathrm{M} /(\mathrm{Cl} \Phi)_{2} \mathrm{PSSH}\right) / \mathrm{TOPO}$ complexes, no doubt due to the stronger $\mathrm{M}-\mathrm{S}_{(\mathrm{Cl \Phi})_{2} \mathrm{PSSH}}$ bonds formed. In conclusion, each co-extractant $\mathrm{B}$ has its specific influence.

\section{Donor properties of co-extractants B}

The different $R_{\mathrm{Eu}-\mathrm{S}}$ distances in $\mathrm{Eu} /(\mathrm{Cl} \Phi)_{2} \mathrm{PSSH} / \mathrm{B}$ complexes compared with $\mathrm{Eu} /(\mathrm{Cl} \Phi)_{2} \mathrm{PSSH}$ reflect the additional effects due to the change in basicity of the $\mathrm{S}$ atoms and the change of $\mathrm{Eu}-\mathrm{S} / \mathrm{Eu}-\mathrm{O}$ bond energies caused by electron transfer within the $\mathrm{O} \Leftrightarrow \mathrm{M}(\mathrm{III}) \Leftrightarrow \mathrm{S}$ system. This process is mainly thought to result in the enthalpy mechanism of $\mathrm{M}-\mathrm{S}$ bond reconstruction in the complexes. Another aspect of the change in $\mathrm{M}-\mathrm{S}$ distances is the steric effect, that is the arrangement of the soft $S$ atoms around the cation. This process is mainly thought to 
result in the entropy mechanism of $\mathrm{M}-\mathrm{S}$ bond reconstruction during the synergistic extraction of $\mathrm{M}$ (III). Caution is therefore necessary with regard to these qualitative proposals because both effects are usually superimposed in extraction data.

Keeping this in mind, these effects can be considered using quantum chemical calculations of the effective charges in the co-extractants. In fact, we proposed that the synergistic effect of the B molecules depends on the basicity of the hard oxygen atom in accordance with the statement: the more negative the charge on the oxygen atom in the co-extractant, the higher its donor ability, and the larger the distribution ratios $D_{\mathrm{Am} \text { (III) }}$ and $\mathrm{D}_{\mathrm{Eu}(\mathrm{III})}$. The effective charges $Q(\mathrm{O})$ were calculated for all phosphates and phosphine oxides $\mathrm{B}$ using an ab initio method with a $6-31 \mathrm{G}^{*}$ basis set. The correlation $\left(R^{2}=0.79\right)$ between the experimental values $\log D_{\mathrm{Am}}$ and $Q(\mathrm{O})$ is quantitatively in line with the above statement [Fig. 8(a)]. Note that the basicity of the hard oxygen atoms in phosphates (TBP, THP, TOP, T2EHP and TAP) is almost the same. According to the correlation, their Am(III) extractability should be similar. Consequently, the enthalpy role in the formation of $\mathrm{Am} /(\mathrm{Cl} \Phi)_{2} \mathrm{PSSH} / \mathrm{B}$ complexes is thought to be significant for all co-extractants.

Fig. 8(b) shows the correlation between $\log D_{\mathrm{Eu}(\mathrm{III})}$ and $Q(\mathrm{O})$. This correlation is not as good as that with $\log D_{\text {Am(III) }}$. In the case of $\mathrm{Eu}(\mathrm{III})$, the synergistic effect sharply decreases from TBP to TOP and T2EHP [which have similar $Q(\mathrm{O})$ ], meaning that the extraction mechanism differs from that for Am(III). We can again conclude that, thermodynamically, the mechanism of Eu(III) extraction with TOP and T2EHP differs from that for Am(III). This is possibly due to different enthalpy/entropy contributions. The enthalpy extraction mechanism is certainly due to the greater covalency of Am-S bonds in comparison with $\mathrm{Eu}-\mathrm{S}$ bonds.

Finally, the donor properties of B molecules with respect to the synergistic effect can be classed as strong (TOPO, TBPO, BPOPO and TPPO), intermediate (TBP, THP, TOP, T2EHP and TAP) and weak (TPP and TMP). The branched coextractant BPOPO, which displays peculiar behavior, has a highly donating oxygen but gives low extractability in its complexes, and is thus excluded from the classification. For the
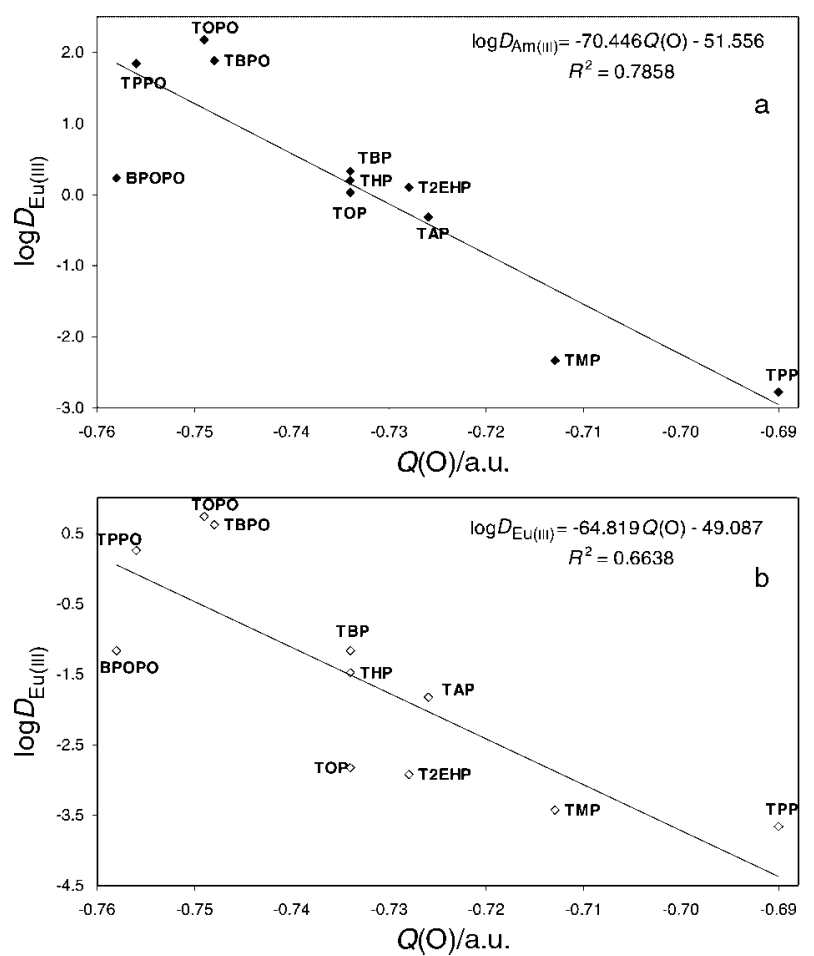

Fig. 8 Correlation between $Q(\mathrm{O})$ of $\mathrm{B}$ and the extractability of (a) Am(III) and (b) Eu(III). strong and weak donor categories, $\Delta_{\mathrm{Am} / \mathrm{Eu}}^{\mathrm{syn}}(\mathrm{B})$ and $\mathrm{SF}_{\mathrm{Am} / \mathrm{Eu}}$ are not high. High $\mathrm{SF}_{\mathrm{Am} / \mathrm{Eu}}$ values are only obtained with the intermediate donors, since in this case, the synergistic effects differ for $\mathrm{Am}$ (III) and $\mathrm{Eu}(\mathrm{III})$.

\section{${ }^{31} \mathrm{P}$ NMR chemical shifts of the molecules $B$ and their synergistic effects}

A correlation was demonstated ${ }^{8}$ between the chemical shifts $\delta\left({ }^{31} \mathrm{P}\right)$ of the neutral organophosphorus co-extractants and the extractability of $\mathrm{Eu}(\mathrm{III})$ and $\mathrm{Am}$ (III) in the synergistic extraction with Cyanex 301. A similar correlation can be also expected for $(\mathrm{Cl} \Phi)_{2} \mathrm{PSSH}+\mathrm{B}$ synergistic systems.

The $\delta\left({ }^{31} \mathrm{P}\right)$ values of all co-extractants used in ref. 7 are not known. The following approach is used to estimate unknown values. The values of $\delta\left({ }^{31} \mathrm{P}\right)$ (relative to $85 \% \mathrm{H}_{3} \mathrm{PO}_{4}$ ) for $\mathrm{R}\left(\mathrm{R}^{\prime} \mathrm{O}\right)_{2} \mathrm{PO}$ molecules, with different $\mathrm{R}$ and $\mathrm{R}^{\prime}$, were shown ${ }^{27}$ to be identical within \pm 2 ppm uncertainty: $\mathrm{C}_{2} \mathrm{H}_{5}\left(\mathrm{C}_{4} \mathrm{H}_{9} \mathrm{O}\right)_{2} \mathrm{PO} \quad(31 \pm 2) ; \quad \mathrm{C}_{4} \overline{\mathrm{H}}_{9}\left(\mathrm{C}_{4} \mathrm{H}_{9} \mathrm{O}\right)_{2} \mathrm{PO} \quad(32 \pm 1) ;$ $\mathrm{C}_{9} \mathrm{H}_{19}\left(\mathrm{C}_{4} \mathrm{H}_{9} \mathrm{O}\right)_{2} \mathrm{PO}(31 \pm 1) ; \mathrm{C}_{10} \mathrm{H}_{21}\left(\mathrm{C}_{4} \mathrm{H}_{9} \mathrm{O}\right)_{2} \mathrm{PO}$ (32 \pm 1$)$; $\mathrm{CH}_{3}\left(\mathrm{C}_{2} \mathrm{H}_{5} \mathrm{O}\right)_{2} \mathrm{PO} \quad(30 \pm 1) ; \mathrm{C}_{2} \mathrm{H}_{5}\left(\mathrm{C}_{2} \mathrm{H}_{5} \mathrm{O}\right)_{2} \mathrm{PO} \quad(32.5 \pm 1) ;$ $\mathrm{C}_{8} \mathrm{H}_{17}\left(\mathrm{C}_{8} \mathrm{H}_{17} \mathrm{O}\right)_{2} \mathrm{PO}(32 \pm 1)$. According to these data, and since $\delta\left({ }^{31} \mathrm{P}\right)$ is $1 \pm 1$ for TBP and TEP $\left[\left(\mathrm{C}_{2} \mathrm{H}_{5}\right)_{3} \mathrm{PO}\right]$, the same value is postulated for the neutral organophosphate molecules TMP, THP, TOP, T2EHP and TAP. The $\delta\left({ }^{31} \mathrm{P}\right)$ value for TPP is assumed to be equal to $-18,{ }^{27}$ and that for TPPO is $23-25 .{ }^{27,28}$ In the case of strongly branched trialkylphosphine oxides, the $\delta\left({ }^{31} \mathrm{P}\right)$ values are lower by $4-8$ than those of $n$-alkylphosphine oxides. ${ }^{27,28} \mathrm{~A}$ value of $\delta\left({ }^{31} \mathrm{P}\right)=36$ is used for BPOPO, as a value $\delta\left({ }^{31} \mathrm{P}\right)=40$ (identical to that of $\mathrm{CMPO}^{8}$ is assumed for TOPO and TBPO.

The effective charges on the $\mathrm{P}$ atoms in $\mathrm{B}$ molecules were also calculated (same method as previously). Fig. 9 shows that these $Q(\mathrm{P})$ values are proportional to the estimated $\delta\left({ }^{31} \mathrm{P}\right)$ values. Two conclusions can be drawn. First, the estimated $\delta\left({ }^{31} \mathrm{P}\right)$ values seem reasonable. Second, $Q(\mathrm{O})$ and $Q(\mathrm{P})$, which are characteristics of the donor ability of the hard coextractant, are both correlated with $\delta\left({ }^{31} \mathrm{P}\right)$. In fact, the $\delta\left({ }^{31} \mathrm{P}\right)$ values of $\mathrm{B}$ can be used to establish correlations with the extractability of $\mathrm{Am}(\mathrm{III})$ and $\mathrm{Eu}(\mathrm{III})$ by $(\mathrm{Cl} \Phi)_{2} \mathrm{PSSH}+\mathrm{B}$ synergistic mixtures.

Fig. 10 shows the correlation between $\delta\left({ }^{31} \mathrm{P}\right)$ of $\mathrm{B}$ and $\log$ $D_{\mathrm{M}(\mathrm{III})}$ corresponding to $(\mathrm{Cl} \Phi)_{2} \mathrm{PSSH}+\mathrm{B}$ synergistic mixtures. The nearly equal values of $\log D_{\text {Am(III) }}$ with TBP, THP, TOP and T2EHP are in good agreement with the $\delta\left({ }^{31} \mathrm{P}\right)$ shifts in these molecules. This is also in agreement with the $Q(\mathrm{O})$ and $Q(\mathrm{P})$ charges and with the same synergistic effect. These correlations can be interpreted as an enhanced enthalpy effect in the extraction of Am(III) with the co-extractants considered. Note that the TMP ligand is certainly partially present in the aqueous phase, owing to its lower lipophilicity in comparison with the other organophosphates studied. This precludes a simple interpretation of the TMP data.

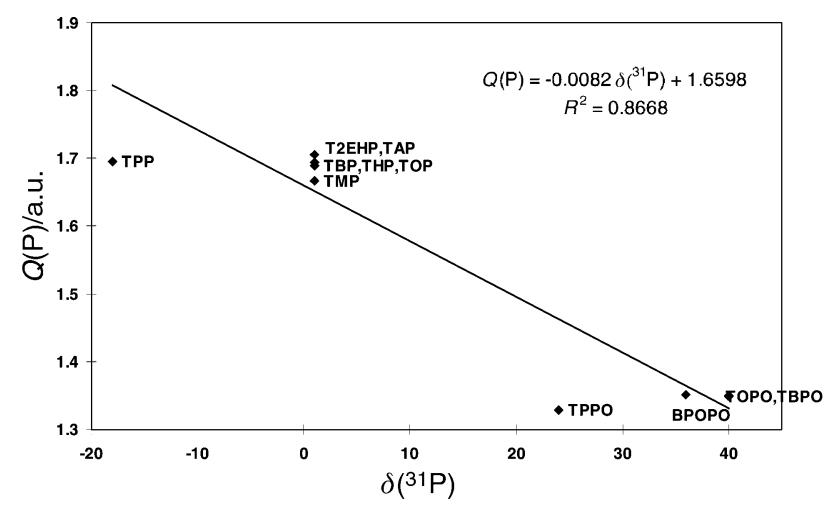

Fig. 9 Correlation between $Q(\mathrm{P})$ of $\mathrm{B}$ and the corresponding $\delta\left({ }^{31} \mathrm{P}\right)$ NMR chemical shift relative to $85 \% \mathrm{H}_{3} \mathrm{PO}_{4}$. 

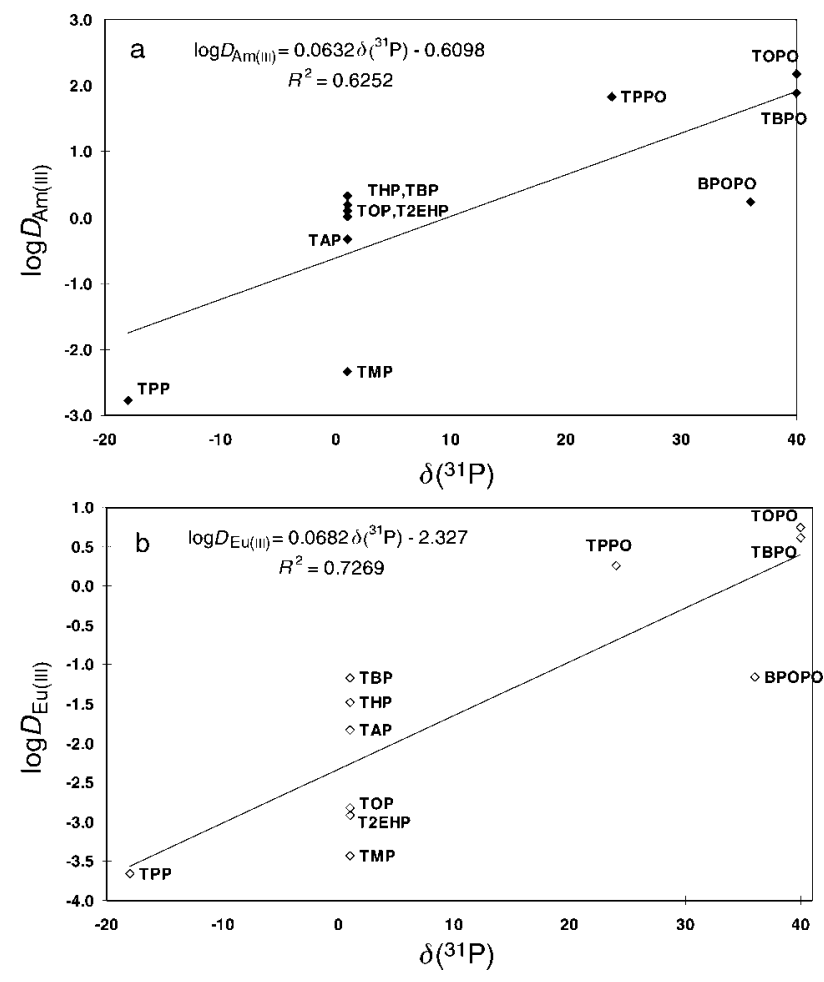

Fig. 10 Correlation between $(a) \log D_{\text {Am(III) }}$ or $(b) \log D_{\text {Eu(III) }}$ and the $\delta\left({ }^{31} \mathrm{P}\right) \mathrm{NMR}$ chemical shift of $\mathrm{B}$ relative to $85 \% \mathrm{H}_{3} \mathrm{PO}_{4}$.

It follows from the correlations in Fig. 10 that a significant effect for $\mathrm{Am} / \mathrm{Eu}$ selectivity arises from the crowding of the branched RO groups in the co-extractants, as in the case of T2EHP. For the extraction of Am(III), the effect of branched RO groups is weak but for $\mathrm{Eu}(\mathrm{III})$ it is strong: for phosphates having the same donor properties but different alkyl groups, there is a relatively small variation of $D_{\text {Am(III) }}$, whereas the variation of $D_{\mathrm{Eu}(\mathrm{III})}$ is large. This different behavior determines the high selectivity observed.

\section{Extraction mechanism with respect to the stability of the $\mathrm{M}(\mathrm{III}) / \mathrm{B}$ and $\mathrm{M}(\mathrm{III}) /(\mathrm{Cl \Phi})_{2}$ PSSH complexes}

Eqn. (4) describes the synergistic effect as the addition of a co-extractant to the complex $\mathrm{M} /(\mathrm{Cl} \Phi)_{2} \mathrm{PSSH}$. We shall now consider another way to form the mixed complex $\mathrm{M} /(\mathrm{Cl} \Phi)_{2} \mathrm{PSSH} / \mathrm{B}$ through the interaction of the two parent complexes, according to the schematic reaction (6) characterized by an equilibrium constant $K_{\text {stab }}$.

$$
\mathrm{M} /(\mathrm{Cl} \Phi)_{2} \mathrm{PSSH}+\mathrm{M} / \mathrm{B} \leftrightarrow \mathrm{M} /(\mathrm{Cl} \Phi)_{2} \mathrm{PSSH} / \mathrm{B}+\mathrm{M}
$$

The thermodynamics of mixed complex formation from parent complexes was previously described ${ }^{29}$ using the stabilization constant, $K_{\text {stab }}$. Since the qualitative aspects of the extraction mechanism are mainly considered here, instead of $K_{\text {stab }}$ the proportional term $\Delta_{\mathrm{M}}^{\text {stab }}(\mathrm{B})$ is used:

$$
\Delta_{\mathbf{M}}^{\text {stab }}(\mathbf{B})=\log D_{\mathbf{M} /(\mathrm{Cl} \Phi)_{2} \mathrm{OSSH} / \mathbf{B}}-\log D_{\mathbf{M} / \mathbf{B}}-\log D_{\mathbf{M} /(\mathrm{Cl} \Phi)_{2} \mathbf{P S S H}}
$$

Comparison of eqn. (4) and (7) leads to:

$$
\Delta_{\mathbf{M}}^{\mathrm{syn}}(\mathrm{B})=\log D_{\mathbf{M} / \mathbf{B}}+\Delta_{\mathbf{M}}^{\mathrm{stab}}(\mathrm{B})
$$

meaning that the synergistic effect involves two parameters characterizing the stabilization of the mixed complex and the formation of the $\mathrm{M} / \mathrm{B}$ complex. Considering only the differ- ence in parameters between Am(III) and $\mathrm{Eu}(\mathrm{III})$, the following equation can be introduced:

$$
\log \mathrm{SF}_{\mathrm{Am} / \mathrm{Eu}}=\Delta_{\mathrm{Am} / \mathrm{Eu}}^{\mathrm{M} /(\mathrm{Cl})_{2} \mathrm{PSSH}}+\Delta_{\mathrm{Am} / \mathrm{Eu}}^{\mathrm{M} / \mathrm{B}}+\Delta_{\mathrm{Am} / \mathrm{Eu}}^{\mathrm{stab}}(\mathrm{B})
$$

with:

$$
\begin{gathered}
\log \mathrm{SF}_{\mathrm{Am} / \mathrm{Eu}}=\log D_{\mathrm{Am} /(\mathrm{Cl} \Phi)_{2} \mathrm{PSSH} / \mathrm{B}}-\log D_{\mathrm{Eu} /(\mathrm{Cl} \Phi)_{2} \mathrm{PSSH} / \mathrm{B}} \\
\Delta_{\mathrm{Am} / \mathrm{Eu}}^{\mathrm{M} / \mathrm{Cl})_{2} \mathrm{PSSH}}=\log D_{\mathrm{Am} /(\mathrm{Cl} \Phi)_{2} \mathrm{PSSH}}-\log D_{\mathrm{Eu} /(\mathrm{Cl} \Phi)_{2} \mathrm{PSSH}} \\
\Delta_{\mathrm{Am} / \mathrm{Eu}}^{\mathrm{M} / \mathrm{B}}=\log D_{\mathrm{Am} / \mathrm{B}}-\log D_{\mathrm{Eu} / \mathrm{B}} \\
\Delta_{\mathrm{Am} / \mathrm{Eu}}^{\mathrm{stab}}(\mathrm{B})=\Delta_{\mathrm{Am}}^{\mathrm{stab}}(\mathrm{B})-\Delta_{\mathrm{Eu}}^{\mathrm{stab}}(\mathrm{B})
\end{gathered}
$$

This model is only qualitative and has been proposed to analyze the trend in the change of contributions of different terms for the overall selectivity $\log \mathrm{SF}_{\mathrm{Am} / \mathrm{Eu}}$. The parameters in eqn. (10) and (11) are known. The values of and $\log D_{\mathbf{M} / \mathbf{B}}$

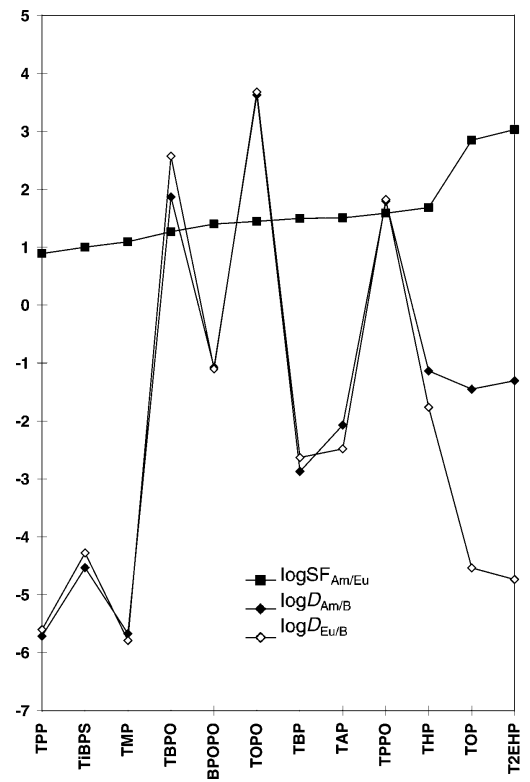

Fig. 11 Comparison between the Am/Eu selectivity and the stabilization of the $\mathrm{M} / \mathrm{B}$ parent complexes for 12 co-extractants $\mathrm{B}$.

Table 9 Different contributions to the formation of mixed complexes from eqn. (10) and (11) $)^{a}$

\begin{tabular}{llrrr}
\hline \multirow{2}{*}{ B } & M(III) & $\log D_{\mathbf{M} /(\mathrm{Cl \Phi})_{2} \text { PSSH/B }}$ & $\log D_{\mathbf{M} / \mathbf{B}}$ & $\Delta_{\mathbf{M}}^{\text {stab }}(\mathrm{B})$ \\
\hline TMP & Eu(III) & -2.34 & -5.67 & 5.64 \\
& Am(III) & -3.43 & -5.79 & 5.01 \\
TBP & Eu(III) & 0.33 & -2.87 & 5.51 \\
& Am(III) & -1.17 & -2.63 & 4.11 \\
THP & Eu(III) & 0.20 & -1.14 & 3.65 \\
& Am(III) & -1.48 & -1.76 & 2.93 \\
TOP & Eu(III) & 0.03 & -1.45 & 3.79 \\
& Am(III) & -2.82 & -4.54 & 4.36 \\
T2EHP & Eu(III) & 0.11 & -1.30 & 3.72 \\
& Am(III) & -2.92 & -4.74 & 4.46 \\
TPP & Eu(III) & -2.77 & -5.71 & 5.25 \\
& Am(III) & -3.66 & -5.60 & 4.59 \\
TAP & Eu(III) & -0.32 & -2.07 & 4.06 \\
& Am(III) & -1.83 & -2.48 & 3.30 \\
TBPO & Eu(III) & 1.88 & 1.87 & 2.32 \\
& Am(III) & 0.62 & 2.57 & 0.70 \\
TOPO & Eu(III) & 2.18 & 3.63 & 0.86 \\
& Am(III) & 0.74 & 3.68 & -0.29 \\
TPPO & Eu(III) & 1.84 & 1.79 & 2.36 \\
& Am(III) & 0.26 & 1.83 & 1.08 \\
BPOPO & Eu(III) & 0.24 & -1.07 & 3.62 \\
TiBPS & Am(III) & -1.16 & -1.10 & 2.59 \\
& Eu(III) & -1.70 & -4.53 & 5.14 \\
& Am(III) & -2.70 & -4.28 & 4.23
\end{tabular}

${ }^{a} \log D_{\mathrm{M} /(\mathrm{Cl \Phi})_{2} \mathrm{PSSH}}=-2.31$ for $\mathrm{Eu}(\mathrm{III})$ and -2.65 for $\mathrm{Am}(\mathrm{III})$. 


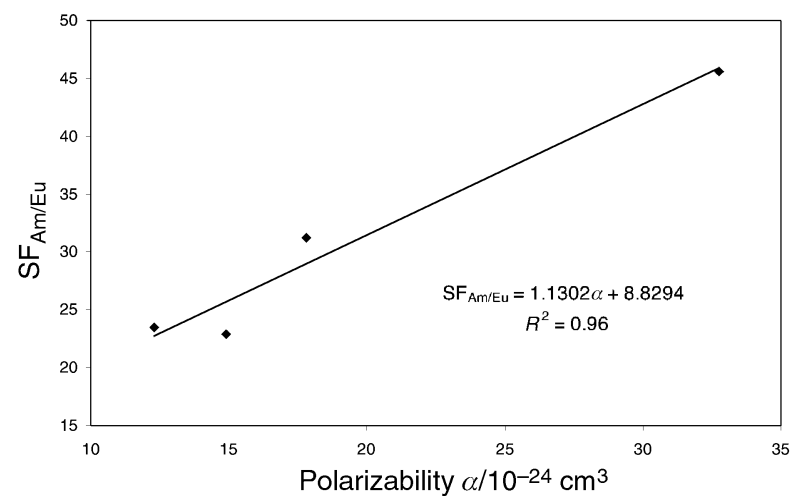

Fig. 12 Correlation between $\mathrm{SF}_{\mathrm{Am} / \mathrm{Eu}}$ and the polarizability of diluent molecules for the synergistic mixture $(\mathrm{Cl} \Phi)_{2} \mathrm{PSSH}+\mathrm{TOPO}$.

and $\Delta_{\mathrm{M}}^{\mathrm{stab}}(\mathrm{B})$ are calculated as follows. Using the data from ref. $8, \Delta_{\mathbf{M}}^{\text {stab }}(\mathrm{B})$ were calculated for $\mathrm{B}=\mathrm{TBP}, \mathrm{TPP}$ and TOPO. All other $\Delta_{\mathrm{M}}^{\text {stab }}(\mathrm{B})$ values can then be derived from the correlation $\Delta_{\mathrm{M}}^{\mathrm{stab}}(\mathrm{B}) v s . \log \mathrm{SF}_{\mathrm{Am} / \mathrm{Eu}} \cdot \log D_{\mathrm{M} / \mathrm{B}}$ values for $\mathrm{Am}(\mathrm{III})$ and $\mathrm{Eu}(\mathrm{III})$ were determined from eqn. (7) and (8).

All the results are summarized in Table 9 while Fig. 11 compares some of the terms calculated from eqn. (7) and (8) for different B. This suggests the following remarks. The extractability of M(III) by synergistic mixtures is the result of competition between the stabilization (or destabilization) of mixed complexes and the destabilization (or stabilization ) of the parent complexes $\mathrm{M} / \mathrm{B}$. The effects are diametrically opposed according to the following: the weaker the $\mathrm{M}-\mathrm{O}$ bond, the stronger the $\mathrm{M}-\mathrm{S}$ bond. Three kinds of complexes can be observed. (i) Weak M/B complexes for both cations, with $\log D_{\mathrm{Am} / \mathrm{B}}$ close to $\log D_{\mathrm{Eu} / \mathrm{B}}$, for $\mathrm{B}=\mathrm{TPP}, \mathrm{T} i \mathrm{BPS}$ and TMP. Low $\mathrm{Am} / \mathrm{Eu}$ selectivities are observed in this case. (ii) Strong M/B complexes for both cations, with $\log D_{\mathrm{Am} / \mathrm{B}}>\log$ $D_{\mathrm{Eu} / \mathrm{B}}$, for B = TBP, TAP, THP, TOPO, TPPO, BPOPO and TBPO, which results in intermediate $\mathrm{Am} / \mathrm{Eu}$ selectivities. (iii) Weak M/B complexes with $\log D_{\mathrm{Am} / \mathbf{B}} \gg \log D_{\mathrm{Eu} / \mathbf{B}}$, for $\mathrm{B}=\mathrm{T} 2 \mathrm{EHP}$ and TOP. This corresponds to a strong reversible stabilization effect, especially for Am(III) and, as a result, high $\mathrm{Am} / \mathrm{Eu}$ selectivity is observed.

\section{Influence of the diluent}

The influence of the type of diluent on the extraction of traces of $\mathrm{Am}(\mathrm{III})$ and $\mathrm{Eu}(\mathrm{III})$ by $0.5 \mathrm{M}(\mathrm{Cl} \Phi)_{2} \mathrm{PSSH}+0.25 \mathrm{M}$ TOPO from nitric acid was previously investigated. ${ }^{7}$ To interpret the data, M(III) extraction properties are compared with the polarizability of the diluent molecules. It is well known that the polarizability of a molecule increases with molecular size, and it was observed ${ }^{14,30}$ that polarizability runs parallel to covalency or softness. Linear relationships were observed between $\log D_{\mathrm{M}(\mathrm{III})}$ values and the polarizability of the diluent molecules: (i) for $\mathrm{Am}$ (III) $\log D_{\mathrm{Am} \text { (III) }}=0.04 \alpha+0.38$ (with $R^{2}=0.93$ ) and (ii) for $\mathrm{Eu}$ (III) $\log D_{\mathrm{Eu} \text { (III) }}=0.03 \alpha+0.81$ (with $\left.R^{2}=0.94\right)$. Fig. 12 shows that the selectivity, $\mathrm{SF}_{\mathrm{Am} / \mathrm{Eu}}$, increases with increasing polarizability of the diluent molecules. Diluent molecules with large volumes and branched structures are expected to lead to increasing $\mathrm{Am} / \mathrm{Eu}$ selectivity.

\section{Conclusions}

The present work demonstrates that Pearson's classification of acids and bases into hard, soft and intermediate appears to be incomplete for its application to the selective separation of trivalent lanthanides and actinides by liquid-liquid extraction. The insufficiencies concern (i) the change in the hardness of f-block elements across the series and (ii) the relative affinity of donor atoms (here $\mathrm{O}$ and $\mathrm{S}$ ) for the complexation of $\mathrm{Ln}(\mathrm{III})$ and An(III).
Although trivalent lanthanides and actinides can be considered as hard acids, it is shown that the quantitative treatment of Pearson's ideas concerning the ability of an acid to accept electrons or of a base to give electrons, ${ }^{11}$ results in a wide hardness variation across the lanthanide and actinide series. In the conventional classification, ${ }^{12-14}$ the hard cations $\mathrm{Am}$ (III) and Eu(III) prefer to coordinate with hard bases, but the experimental results show that $\mathrm{Am}$ (III) and $\mathrm{Eu}$ (III) form complexes with the soft dithiophosphonate and dithiophosphonic acid ligands.

Moreover, under Klopman's classification, ${ }^{11}$ Eu(III) appears to be a less hard acid than Am(III), but again experience reveals the opposite. It is proved that covalency effect(s) can change the respective parameters of hardness of $\operatorname{Ln}(\mathrm{III})$ and An(III) ions.

Finally, the key problem in the classic theory of hardness/ softness concerning the combination of soft and hard donor atoms in the first coordination sphere of An(III) or Ln(III) may not be clearly understood. This problem concerns the theory of synergism and the formation of mixed complexes. It is unclear whether hard Am(III) or Eu(III) complexation with the soft $\mathrm{R}_{2} \mathrm{PSS}^{-}$ligands will be strengthened by the presence of groups bearing hard oxygen atoms in neutral co-extractants. It is shown that the $\mathrm{M}-\mathrm{S}$ bonds may be strengthened or weakened depending on the donor ability of the hard oxygen atoms.

These fundamental problems in the application of hardness/ softness theory to the chemistry of Am(III) and $\mathrm{Eu}$ (III) were solved through the study of their synergistic selective extraction from aqueous nitric acid solution using di(chlorophenyl)dithiophosphinic acid and neutral organophosphorus co-extractants. Several analyses are discussed in this paper: (i) quantum chemical calculations of the donor properties of coextractants, (ii) analysis of $\delta\left({ }^{31} \mathrm{P}\right) \mathrm{NMR}$ chemical shifts of the co-extractants, (iii) analysis of the $\mathrm{S} \rightarrow \mathrm{Eu}(\mathrm{III})$ charge transfer energy in mixed $\mathrm{Eu} /(\mathrm{Cl} \Phi)_{2} \mathrm{PSSH} / \mathrm{B}$ complexes, (iv) qualitative thermodynamic calculations of the synergistic effect, and (v) evaluation of the $\mathrm{Eu}-\mathrm{S}$ interatomic distances in mixed complexes with several co-extractants B. These analyses suggest a rule of design of hard co-extractants to strengthen (or weaken) the $\mathrm{M}-\mathrm{S}$ bonds: the addition of neutral strong donor coextractants bearing $\mathrm{O}$ atoms to an existing S-ligand weakens the $\mathrm{M}-\mathrm{S}$ bonds and increases the $\mathrm{M}-\mathrm{S}$ distance. The addition of neutral weak donor co-extractants results in the opposite effect.

From the data on the extractability of Eu(III) and Am(III) by $(\mathrm{Cl} \Phi)_{2} \mathrm{PSSH}+\mathrm{B}$ mixtures, where $\mathrm{B}$ are phosphates, we can conclude that steric hindrance exerts a greater effect on the extraction of $\mathrm{Eu}(\mathrm{III})$ than Am(III). The importance of such steric effects was also pointed out recently by Baaden et al. in the complexation of $\mathrm{Ln}$ (III) ions by $\mathrm{R}_{2} \mathrm{PSSH}$ acidic ligands with different $\mathrm{R}$ groups. ${ }^{31}$ In the case of $\mathrm{Eu}(\mathrm{III})$, which has a smaller ionic radius than Am(III), we can conclude that the steric effect may be preponderant, whereas in the case of Am(III), which forms more covalent bonds than Eu(III), the donor-acceptor mechanism of extraction appears to predominate.

\section{References}

1 Actinide and Fission Product Partitioning and Transmutation, Status and Assessment Report, Nuclear Energy Agency, Organisation for Economic Cooperation and Development, Issy-lesMoulineaux, France, 1999.

2 Actinide and Fission Product Partitioning and Transmutation, Proceedings of the Fifth International Information Exchange Meeting, Nuclear Energy Agency, Organisation for Economic Cooperation and Development, Issy-les-Moulineaux, France, 1999.

3 Y. Zhu, J. J. Chen and R. Jiao, Solv. Extr. Ion Exch., 1996, 14, 61.

4 G. Modolo and R. Odoj, J. Alloys Compd., 1998, 271/273, 248. 
5 (a) C. Hill, C. Madic, P. Baron, M. Ozawa and Y. Tanaka, J. Alloys Compd., 1998, 271/273, 59; (b) C. Hill, C. Madic and G. Modolo, Actinide and Fission Product Partitioning and Transmutation, Proceedings of the Fifth International Information Exchange Meeting, Nuclear Energy Agency, Organisation for Economic Cooperation and Development, Issy-les-Moulineaux, France, 1999, p. 483

6 G. D. Jarvinen, R. E. Barrans, N. C. Schroeder, K. L. Wade, M. M. Jones, B. F. Smith, J. L. Mills, G. Howard, H. Freiser and S. Muralidharan, in Separations of $f$ Elements, ed. K. L. Nash and G. R. Choppin, Plenum Press, New York, 1995, p. 43.

7 (a) G. Modolo and R. Odoj, Solv. Extr. Ion Exch., 1999, 17, 33; (b) F. Fournet and C. Hill, unpublished results.

8 G. Ionova, C. Madic, C. Hill, C. Rabbe, S. Ionov, R. Guillaumont and J. C. Krupa, Solv. Extr. Ion Exch., 2001, in press.

9 M. J. Frisch, G. W. Trucks, H. B. Schlegel, G. E. Scuseria, M. A. Robb, J. R. Cheeseman, V. G. Zakrzewski, J. A. Montgomery, Jr., R. E. Stratmann, J. C. Burant, S. Dapprich, J. M. Millam, A. D. Daniels, K. N. Kudin, M. C. Strain, O. Farkas, J. Tomasi, V. Barone, M. Cossi, R. Cammi, B. Mennucci, C. Pomelli, C. Adamo, S. Clifford, J. Ochterski, G. A. Petersson, P. Y. Ayala, Q. Cui, K. Morokuma, D. K. Malick, A. D. Rabuck, K. Raghavachari, J. B. Foresman, J. Cioslowski, J. V. Ortiz, B. B. Stefanov, G. Liu, A. Liashenko, P. Piskorz, I. Komaromi, R. Gomperts, R. L. Martin, D. J. Fox, T. Keith, M. A. Al-Laham, C. Y. Peng, A. Nanayakkara, C. Gonzalez, M. Challacombe, P. M. W. Gill, B. Johnson, W. Chen, M. W. Wong, J. L. Andres, C. Gonzalez, M. Head-Gordon, E. S. Replogle and J. A. Pople, GAUSSIAN 98, Gaussian, Inc., Pittsburgh, PA, 1998.

10 (a) D. Pattée, PhD Thesis, Université Louis Pasteur, Strasbourg, France, 1986; (b) D. Pattée and C. Musikas, J. Less-Common Met., 1986, 122, 295.

11 G. Klopman, J. Am. Chem. Soc., 1968, 90, 223.

12 R. Pearson, J. Chem. Educ., 1968, 45, 643.

13 R. Pearson, Chem. Brit., 1967, 3, 103.

14 Hard and Soft Acids and Bases. Benchmark Papers in Inorganic Chemistry, ed. R. G. Pearson, series ed. H. H. Sisler, Dowden, Hutchinson \& Ross, Inc., Stroudsburg, PA, 1973, p. 300.
15 A. A. Pinkerton and D. Schwarzenbach, J. Chem. Soc., Dalton Trans., 1976, 2465

16 A. E. Martell and R. D. Hancock, Metal Complexes in Aqueous Solutions, Plenum Press, New York, 1996.

17 R. S. Drago, G. C. Vogel and T. E. Needham, J. Am. Chem. Soc., 1971, 93, 6014

18 R. D. Hancock and F. Marsicano, Inorg. Chem., 1980, 19, 2709.

19 CODATA recommended key values for thermodynamics: $J$. Chem. Thermodyn., 1978, 10, 903.

20 W. C. Martin, J. Opt. Soc. Am., 1971, 61, 1672.

21 L. R. Morss, in The Chemistry of the Actinide Elements, 2nd edn., ed. J. J. Katz, G. T. Seaborg and L. R. Morss, Chapman and Hall, London, New York, 1986, p. 1278.

22 Y. J. J. Chen and R. Jiao, Solv. Extr. Ion Exch., 1996, 14, 61.

23 L. J. Nugent, R. D. Baybarz, J. L. Burnett and J. L. Ryan, J. Phys. Chem., 1973, 77, 1528 .

24 L. Morss, in Handbook on the Physics and Chemistry of Rare Earths, ed. K. A. Gschneider, Jr., L. Eyring, G. R. Choppin and G. H. Lander, Elsevier Science B.V., Amsterdam, 1994, vol. 18, p. 239.

25 V. Caglioti, G. Sartori, C. Furlani, E. Cervone and P. Cancellieri, Proc. Int. Conf. Coord. Chem., 9th, 1966, 121.

26 D. Kalina, G. Mason and E. P. Horwitz, J. Inorg. Nucl. Chem., 1981, 43, 579 .

27 (a) J. R. Wazer, J. Am. Chem. Soc., 1956, 78, 5709; (b) S. P. Ionov and G. V. Ionova, Russ. J. Phys. Chem., 1969, 43, 458.

28 E. Nifantiev and L. Vasyaninia, Spectroscopy of ${ }^{31} P N M R$, Moscow State Pedagogical Institute (MGPI), Lenin, Moscow, 1986.

29 Y. Marcus and I. Eliezer, Coord. Chem. Rev., 1969, 4, 273.

30 G. Ionova, C. Madic and R. Guillaumont, in Proceedings of Journées des Actinides 1997, ed. J. Aupiais and T. Thevenin, Dijon, France, 1997, p. 43.

31 M. Baaden, F. Berny, C. Boehme, N. Muzet, R. Schurhammer and G. Wipff, J. Alloys Compd., 2000, 303-304, 104. 